\title{
Metformin impairs cisplatin resistance effects in A549 lung cancer cells through mTOR signaling and other metabolic pathways
}

\author{
ANA PAULA MORELLI ${ }^{1}$, THARCÍSIO CITRÂNGULO TORTELLI JR ${ }^{2}$, ISADORA CAROLINA BETIM PAVAN ${ }^{1,3}$, \\ FERNANDO RIBACK SILVA ${ }^{3}$, DANIELA CAMPOS GRANATO ${ }^{4}$, GUILHERME FRANCISCO PERUCA ${ }^{5}$, \\ BIANCA ALVES PAULETTI ${ }^{4}$, ROMÊNIA RAMOS DOMINGUES ${ }^{4}$, ROSANGELA MARIA NEVES BEZERRA ${ }^{1}$, \\ LEANDRO PEREIRA DE MOURA ${ }^{5}$, ADRIANA FRANCO PAES LEME ${ }^{4}$, \\ ROGER CHAMMAS ${ }^{2}$ and FERNANDO MOREIRA SIMABUCO ${ }^{1}$
}

\begin{abstract}
${ }^{1}$ Multidisciplinary Laboratory of Food and Health, School of Applied Sciences, State University of Campinas, Limeira, SP 13484-350; ${ }^{2}$ Centro de Investigação Translacional em Oncologia, Departamento de Radiologia e Oncologia, Faculdade de Medicina da Universidade de São Paulo and Instituto do Câncer do Estado de São Paulo, São Paulo, SP 04021-001; ${ }^{3}$ Laboratory of Signaling Mechanisms, School of Pharmaceutical Sciences, State University of Campinas, Campinas, SP 13083-871; ${ }^{4}$ Brazilian Biosciences National Laboratory, Brazilian Center for Research in Energy and Materials, Campinas, SP 13083-970; ${ }^{5}$ Exercise Cell Biology Laboratory, School of Applied Sciences, State University of Campinas, Limeira, SP 13484-350, Brazil
\end{abstract}

Received July 23, 2020; Accepted January 19, 2021

DOI: $10.3892 / \mathrm{ijo} .2021 .5208$

\begin{abstract}
Lung cancer is the leading cause of cancer-associated death worldwide and exhibits intrinsic and acquired therapeutic resistance to cisplatin (CIS). The present study investigated the role of mTOR signaling and other signaling pathways after metformin (MET) treatment in control and cisplatin-resistant A549 cells, mapping pathways and possible targets involved in CIS sensitivity. MTT, flow cytometry, clonogenic assay, western blotting, proteomic analysis using the Stable Isotope Labeling by Amino acids in Cell culture (SILAC) approach and reverse transcription-quantitative PCR were performed. The results revealed that CIS treatment induced mTOR signaling pathway overactivation, and the mTOR status was restored by MET. MET and the mTOR inhibitor rapamycin (RAPA) decreased the viability in control and resistant cells, and decreased the cell size increase induced by CIS. In control cells, MET and RAPA decreased colony formation after $72 \mathrm{~h}$ and decreased $\mathrm{IC}_{50}$ values, potentiating the effects of CIS. Proteomics analysis revealed important pathways regulated by MET, including transcription, RNA processing and IL-12-mediated signaling. In CIS-resistant cells, MET regulated the apoptotic process, oxidative stress
\end{abstract}

Correspondence to: Dr Fernando Moreira Simabuco, Multidisciplinary Laboratory of Food and Health, School of Applied Sciences, State University of Campinas, Rua Pedro Zaccaria 1300, Jardim São Paulo, Limeira, SP 13484-350, Brazil

E-mail: simabuco@gmail.com

Key words: lung cancer, cisplatin resistance, metformin, mTOR, proteomics and $\mathrm{G}_{2} / \mathrm{M}$ transition. Annexin 4 (ANXA4) and superoxide dismutase 2 (SOD2), involved in apoptosis and oxidative stress, respectively, were chosen to validate the SILAC analysis and may represent potential therapeutic targets for lung cancer treatment. In conclusion, the chemosensitizing and antiproliferative effects of MET were associated with mTOR signaling and with potential novel targets, such as ANXA4 and SOD2, in human lung cancer cells.

\section{Introduction}

Cancer is a relevant global public health problem, considered as the most important barrier to increasing global life expectancy in the 21 st century (1). Each year, $88 \%$ of people diagnosed with lung cancer have a death outcome, accounting for 2,093,876 new cases and 1,761,007 deaths worldwide in 2018 (1). Despite the development of early diagnosis methods and new treatment modalities, the 5-year survival rate of patients with lung cancer remains poor, increasing only by $3.7 \%$ between 1985 and 2004 (2). In advanced stages, when surgical resection is not possible, chemotherapy using platinum drugs, including cisplatin, is the current standard treatment for non-small cell lung cancer (NSCLC) $(3,4)$, although it is strongly associated with intrinsic and acquired resistance (5).

The common strategy used to improve the sensitivity to platinum compounds and overcome their resistance is the combination with radiotherapy, antibodies, selective inhibitors or already prescribed drugs (3). Studies exploring the molecular profile characterization of lung cancer have allowed the development of targeted therapies, such as monoclonal antibodies against vascular endothelial growth factor, epidermal growth factor receptor (6), programmed cell death 1 ligand 1 (7), anaplastic lymphoma kinase (8), proto-oncogene tyrosine-protein kinase ROS1 (9) and serine/threonine-protein 
kinase B-raf (10) inhibitors, replacing or enhancing basic cytotoxic therapies (11).

Repurposing drugs already approved by the Food and Drug Administration can speed up therapeutic management due to overcoming the steps of new drug development. Metformin, a well-known oral antidiabetic drug, is widely associated with a decreased cancer risk (12) and increases the chemotherapeutic effects for different types of cancer, including endometrial cancer $(13,14)$, osteosarcoma $(15)$, hepatocarcinoma (16), non-small cell lung cancer (17) and gastric cancer (18). Metformin decreases the proliferation of lung cancer cells treated with cisplatin compared with cisplatin treatment alone (19) and sensitizes cells to tyrosine kinase inhibitors (20) and crizotinib treatment through the insulin growth factor 1 (IGF1) signaling pathway (21). The mechanisms by which metformin exerts antineoplastic effects remain unclear, but the AMPK-driven inhibition of mTOR seems to be required for its antimitotic activity (22).

The serine/threonine kinase mTOR is a widely evolutionarily conserved protein essential for cellular metabolism, acting as a sensor for the availability of nutrients and growth factors (23). Overactivation of the mTOR signaling pathway contributes to several disorders (24) and is associated with a poor cancer prognosis $(25,26)$. Most cases of lung cancer have a mutation in liver kinase B1 (LKB1), such as A549 cells (27), which leads to the partial impairment of AMPK and overactivation of mTOR signaling (28). Studies have revealed that cisplatin sensitivity is associated with mTOR inhibition, especially in LKB1- and KRAS-mutant cancer (29-31). Despite the overactivation of mTOR signaling, the lack of LKB1 can also sensitize to metformin due to the inability to restore energy homeostasis $(32,33)$. This makes mTOR signaling an important regulatory mechanism in lung cancer progression and metformin treatment.

The present study aimed to investigate the effects of metformin in cisplatin resistance and regulation of metabolic cancer pathways, including mTOR signaling, in lung cancer. The proteomes upon metformin treatment in the context of resistance and sensitivity to cisplatin in A549 cells were compared, revealing new possible molecular strategies and targets for NSCLC treatment to overcome cisplatin resistance.

\section{Materials and methods}

Cell culture. A549 cells were maintained in HAM-F12 medium (Gibco; Thermo Fisher Scientific, Inc.) supplemented with 10\% FBS (Gibco; Thermo Fisher Scientific, Inc.), penicillin $(100 \mathrm{U} / \mathrm{ml})$ and streptomycin $(100 \mu \mathrm{g} / \mathrm{ml})$. Cells were maintained at $37^{\circ} \mathrm{C}$ in a humidified atmosphere containing $5 \% \mathrm{CO}_{2}$. Cells were treated at $37^{\circ} \mathrm{C}$ with $10 \mu \mathrm{M}$ cisplatin (Sigma-Aldrich; Merck KGaA) for $72 \mathrm{~h}$ to generate the resistant population [CIS vs. control (C)] and were exposed to $10 \mathrm{mM}$ metformin (Sigma-Aldrich; Merck KGaA) (MET or CISMET) or $100 \mathrm{nM}$ rapamycin at $37^{\circ} \mathrm{C}$ (Sigma-Aldrich; Merck KGaA) (RAPA or CISRAPA) for 24,48 or $72 \mathrm{~h}$ according to different assays.

MTT viability assay. A549 cells were seeded at a density of $3 \times 10^{4}$ cells/well for the $\mathrm{C}$ group (sensitive cells) and $9 \times 10^{4}$ cells/well for the CIS population (resistant cells) in 96-well plates and treated with cisplatin for $72 \mathrm{~h}$ and metformin or rapamycin for another $72 \mathrm{~h}$. After incubation, $12 \mathrm{mM}$ MTT solution was added to each well for $2 \mathrm{~h}$ at $37^{\circ} \mathrm{C}$. The culture medium was aspirated and the formazan crystals were solubilized with a solution of $1 \mathrm{M} \mathrm{HCl}$ :isopropanol $(1: 25)$ for $15 \mathrm{~min}$ at $37^{\circ} \mathrm{C}$, and the absorbance of each sample was measured at $570 \mathrm{~nm}$.

Clonogenic assay and microscopy. A549 cells were seeded at low density in 6-well plates $\left(3 \times 10^{2}\right.$ cells/well), treated with $10 \mathrm{mM}$ metformin or $100 \mathrm{nM}$ rapamycin for $72 \mathrm{~h}$ and incubated for 7 days at $37^{\circ} \mathrm{C}$. After incubation, cells were washed with PBS and stained with $3 \mathrm{ml}$ methylene blue dye $(0.3 \%$ in $50 \%$ ethanol) for $30 \mathrm{~min}$ at room temperature. The plates were washed with deionized water and staining was measured at an absorbance of $590 \mathrm{~nm}$ by eluting with $10 \%$ acetic acid. The size of the colonies was calculated using ImageJ software v1.53 (National Institutes of Health). Colonies $>0.01$ pixel $^{2}$ were considered as hits by the Image J software and were then manually divided into size ranges using Excel (Microsoft Corporation). The size ranges were hits $<1$ pixel $^{2}$, between 1 and 25 pixel $^{2}$ and $>25$ pixel $^{2}$. Images of the cells for morphology analysis were captured using a light microscope coupled to a camera (magnification, x40; Leica Microsystems, Inc.), using scale bars of $100 \mu \mathrm{m}$.

Cell cycle and size analysis. A549 cells were seeded in 6-well plates at a density of $3 \times 10^{5}$ cells/well and treated with $10 \mu \mathrm{M}$ cisplatin for $72 \mathrm{~h}$ and $10 \mathrm{mM}$ metformin or $100 \mathrm{nM}$ rapamycin for $24 \mathrm{~h}$ for cell size analysis or $72 \mathrm{~h}$ for cell cycle analysis. After treatment, cells were washed with $1 \mathrm{X}$ PBS $(0.137 \mathrm{M}$ $\mathrm{NaCl}$ and $0.05 \mathrm{M} \mathrm{NaH}_{2} \mathrm{PO}_{4}, \mathrm{pH} 7.4$ ) and resuspended in $500 \mu \mathrm{l}$ HAM-F12 medium. Cells were centrifuged at $300 \mathrm{x} g$ for $5 \mathrm{~min}$ at room temperature and resuspended in $100 \mu \mathrm{l}$ propidium iodide (PI) solution (0.1\% Triton X-100, $20 \mu \mathrm{g} / \mathrm{ml}$ PI and $10 \mu \mathrm{g} / \mathrm{ml}$ RNAse in PBS) for cell cycle analysis or $100 \mu \mathrm{l}$ PBS for cell size analysis. The PI fluorescence and cell profile were determined using a BD Accuri ${ }^{\mathrm{TM}}$ C6 flow cytometer and analyzed using the BD Accuri ${ }^{\mathrm{TM}}$ software v1.0.264.21 (BD Biosciences).

Western blotting. Protein extracts obtained by lysing cells (50 mM Tris- $\mathrm{Cl}$ pH 7.5, $150 \mathrm{mM} \mathrm{NaCl,} 1 \mathrm{mM}$ EDTA, 1\% Triton X-100, protease inhibitor cocktail and phosphatase inhibitor cocktail) were quantified using a bicinchoninic acid assay and samples containing 20-40 $\mu \mathrm{g}$ of protein were separated by SDS-PAGE ( 8 and $10 \%$ gels). The gels were electrotransferred to $0.45-\mu \mathrm{m}$ nitrocellulose membranes (Bio-Rad Laboratories, Inc.) and the membranes were incubated for $2 \mathrm{~h}$ at room temperature with $5 \%$ non-fat powdered milk dissolved in TBS-Tween (TBST; 50 mM Tris-Cl, pH 7.5; $150 \mathrm{mM} \mathrm{NaCl} ; 0.1 \%$ Tween-20) to saturate unspecific binding sites, followed by an overnight incubation at $4{ }^{\circ} \mathrm{C}$ with primary antibodies. Membranes were washed 3 times with TBST and then incubated with HRP-conjugated goat anti-mouse IgG (Sigma-Aldrich; Merck KGaA; cat. no. AP308P; 1:2,000) and goat anti-rabbit IgG (Sigma-Aldrich; Merck KGaA; cat. no. AP307P; 1:5,000) secondary antibodies for $1 \mathrm{~h}$ at room temperature. Protein bands were visualized using Pierce ${ }^{\mathrm{TM}}$ ECL Western Blotting Substrate (Thermo Fisher Scientific, 
Inc.) and densitometry was performed using ImageJ software v1.53. Primary antibodies (all 1:2,000) against mTOR (cat. no. 2972), phospho-mTOR (Ser2448; cat. no. 2971), AMPK $\alpha$ (cat. no. 5831), phospho-AMPK $\alpha$ (Thr172; cat. no. 50081), p70-S6K1 (cat. no. 2708), phospho-p70-S6K1 (Thr389; cat. no. 9234), S6 (cat. no. 2317), phospho-S6 (Ser240/244; cat. no. 2215) and GAPDH (cat. no. 2118) were purchased from Cell Signaling Technology, Inc.

Reverse transcription-quantitative PCR (RT-qPCR). Total RNA was extracted from A549 cells using TRIzol ${ }^{\circledR}$ (Invitrogen; Thermo Fisher Scientific, Inc.). The cDNA was synthesized using the High Capacity cDNA Reverse Transcription kit with 2,000 ng of total RNA according to the manufacturer's protocol (Thermo Fisher Scientific, Inc.). The qPCR reaction was performed with SYBR Green PCR Master Mix (Applied Biosystems; Thermo Fisher Scientific, Inc.). qPCR was performed with an initial denaturation step at $95^{\circ} \mathrm{C}$ for $10 \mathrm{~min}$ and then 40 cycles of $95^{\circ} \mathrm{C}$ for $15 \mathrm{sec}$ and $60^{\circ} \mathrm{C}$ for $1 \mathrm{~min}$. A melting curve was performed after the PCR from $60^{\circ} \mathrm{C}$ to $95^{\circ} \mathrm{C}$. The $2^{-\Delta \Delta C q}$ method was used for quantification (34). $\beta$-actin was used as the normalizing gene. Samples for this reaction were added in triplicates in a 96-well plate (MicroAmp; Applied Biosystems; Thermo Fisher Scientific, Inc.) for amplification and reading in the Step One Plus Real-Time PCR System (Applied Biosystems; Thermo Fisher Scientific, Inc.). The primers used were designed using Primer-BLAST (35) (National Institutes of Health): Superoxide dismutase 2 (SOD2) forward, 5'-AAGGAACGG GGACACTTACAAA-3' and reverse, 5'-AGCAGTGGAATA AGGCCTGTTG-3'; Annexin 4 (ANXA4) forward, 5'-CAG AGGAACAACCAGGAACTTG-3' and reverse, 5'-CAAGCA GAAGTTCTTCGAGGC-3'; and $\beta$-actin forward, 5'-GCC GCCAGCTCACCAT-3' and reverse, 5'-CCACGATGGAGG GGAAGAC-3'.

Stable isotope labeling by amino acids in cell culture (SILAC). For heavy (H)- or light (L)-lysine labeling experiments, A549 cells were maintained in a T25 flask with SILAC ${ }^{\text {TM }}$ HAMF12 medium (Thermo Fisher Scientific, Inc.) supplemented with $10 \%$ dialyzed FBS without lysine and arginine. To obtain $\mathrm{H}$ and L conditions, SILAC ${ }^{\text {TM }}$ HAMF12 medium was supplemented with ${ }^{13} \mathrm{C} 6 \mathrm{~L}-$ lysine-2 $\mathrm{HCl}(\mathrm{H})$ or ${ }^{12} \mathrm{C} 6 \mathrm{~L}$-lysine-2 $\mathrm{HCl}(\mathrm{L})$ and ${ }^{12} \mathrm{C} 6 \mathrm{~L}$-arginine- $2 \mathrm{HCl}(\mathrm{H}$ and $\mathrm{L})$. The final concentration of amino acids were $0.46 \mathrm{mM}$ (lysine) and $0.47 \mathrm{mM}$ (arginine). After 5 passages, $\mathrm{C}$ and CIS cells were treated in triplicate with $10 \mathrm{mM}$ metformin for $72 \mathrm{~h}$ (CxMET representing the Ctrl population; CISxCISMET representing the CIS population), washed two times with PBS in a 6-well plate and collected using $100 \mu 1$ lysis buffer as aforementioned.

The mixed H-/L-labeled protein sample $(27.5 \mu \mathrm{g}$ of total protein per group) was separated by electrophoresis in reducing 10\% SDS-PAGE, heated for $10 \mathrm{sec}$ in a microwave in Coomassie Brilliant Blue stain (Sigma-Aldrich; Merck KGaA; $2 \%$ Coomassie in $50 \%$ ethanol and $2.5 \%$ acetic acid) and incubated for $1 \mathrm{~h}$ at room temperature. After overnight incubation of the gel for background de-staining, each gel lane was sliced into 10 pieces. The excised sections were unstained twice with a de-staining solution $(50 \%$ ethanol and $2.5 \%$ acetic acid in purified water) in $1.5-\mathrm{ml}$ microtubes to start the gel bands digestion protocol using trypsin. The percentage of isotopic label incorporation was tested according to the following equation: (Ratio H/L x 100)/(Ratio H/L + 1) (36).

Trypsin digestion, mass spectrometry (MS) and data analysis. The protein bands were reduced, alkylated and digested with trypsin overnight at $37^{\circ} \mathrm{C}$. An aliquot of the peptide mixture was separated using a $2-40 \%$ acetonitrile gradient in $0.1 \%$ formic acid using an analytical PicoFrit Column $(20 \mathrm{~cm} \mathrm{x}$ ID75 $\mu \mathrm{m} ; 5-\mu \mathrm{m}$ particle size; New Objective, Inc.), at a flow rate of $300 \mathrm{nl} / \mathrm{min}$ over $35 \mathrm{~min}$. Peptides were analysed using the EASY-nLC II (Proxeon Biosystems) coupled to LTQ Orbitrap Velos (Thermo Fisher Scientific, Inc.), with electrospray ionization in positive mode and set up in the data-dependent acquisition mode. Full scan MS spectra $(\mathrm{m} / \mathrm{z}$ 300-1,600) were acquired in the Orbitrap analyzer after accumulation to a target value of $1 \times 10^{6}$. Resolution in the Orbitrap was set to $r=60,000$, and the 20 most intense peptide ions with charge states $\geq 2$ were sequentially isolated to a target value of 5,000 and fragmented in the linear ion trap by low-energy collision-induced dissociation (normalized collision energy of $35 \%$ ). Three independent experiments were performed.

Bioinformatics analysis. For SILAC data analysis, the raw files were processed using MaxQuant 2012 version 1.3.0.5 (https://www.maxquant.org) and the MS/MS spectra were searched using the Andromeda search engine against the Uniprot Human Protein Database (37) (release 17 February 2016; 91,974 sequences; 36,693,332 amino acid residues). The initial maximal allowed mass tolerance was set to $20 \mathrm{ppm}$ for precursor, $6 \mathrm{ppm}$ in the main search afterward and then to $0.5 \mathrm{Da}$ for fragment ions. Enzyme specificity was set to trypsin with a maximum of two missed cleavages. Carbamidomethylation of cysteine (57.021464 Da) was set as a fixed modification, and oxidation of methionine (15.994915 Da) and protein N-terminal acetylation (42.010565 Da) were selected as variable modifications. The minimum peptide length was set to 6 amino acids, including heavy label Lys6. For protein quantification, a minimum of two ratio counts was set and the 'requantify' and 'match between runs' functions were enabled. The false discovery rates (FDRs) of peptide and protein were both set to 0.01. Data processing was performed using Perseus v.1.2.7.4 available in the MaxQuant database (https://www.maxquant.org/). First, reverse and contaminant entries were excluded from further analysis. A protein ratio intensity between $\mathrm{H}$ and $\mathrm{L}$ was used to compare differential protein expression in the total extract from C and MET cells, and CIS and CISMET treated cells. The protein ratios were calculated from the median of all normalized peptide ratios using unique peptides or peptides assigned to the protein group with the highest number of peptides (razor peptides).

For statistical analysis of differentially expressed proteins, the ratios were converted into $\log 2$ and Student's unpaired t-test was applied on the $\mathrm{C}$ and CMET treated groups and CIS and CISMET treated groups. All MS raw files and search parameter settings associated with the present study are available for download via the PRIDE data repository at https://www. ebi.ac.uk/pride/archive/ (accession no. PXD017645). After the t-test, volcano plots were constructed to each replicate separately 
A

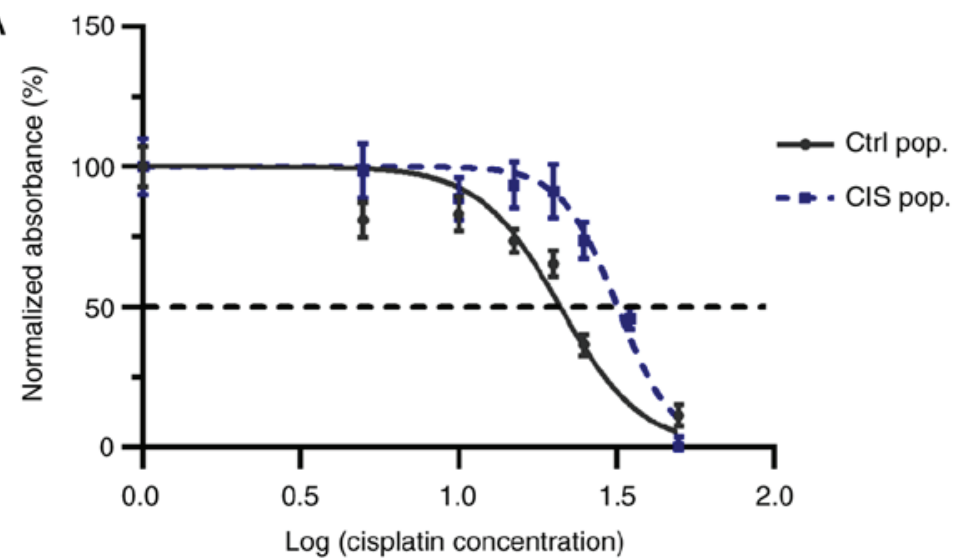

$\mathrm{B}$

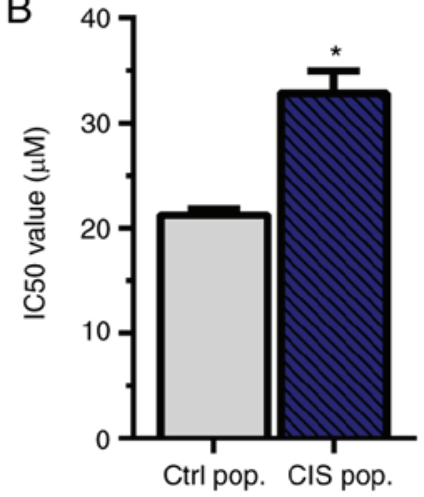

Figure 1. CIS $(10 \mu \mathrm{M})$ generates resistance, increasing the $\mathrm{IC}_{50}$ in A549 lung cancer cells. A549 cells exposed to $10 \mu \mathrm{M}$ CIS (CIS pop) or not (Ctrl pop) for $72 \mathrm{~h}$ were subsequently subjected to different concentrations of CIS and MTT assay was performed. (A) Data was expressed in a non-fit curve of log of cisplatin concentration versus normalized percentage of viability. (B) Bar graph shows the mean with SEM of 3 independent experiments. ${ }^{*} \mathrm{P}<0.05$. CIS, cisplatin; Ctrl, control; pop, population.

using the Volcano Plot Plugin of the OriginLab 2019b software (v9.65; OriginLab) considering $\mathrm{P}<0.05\left[\log _{10}(0.05)=1.3010\right]$ and $\log 2$ ratio $> \pm 1.0$ (fold change of CxMET and CISxCISMET ratio $\mathrm{H} / \mathrm{L}$ normalized) as exclusion parameters. Heatmaps were generated on Morpheus online (https://software.broadinstitute.org/morpheus) considering common proteins in both groups with $\mathrm{P}<0.05$. The heatmap represents the standardized values to robust z-score clustered by Euclidian distance using the average linkage method. Proteome networks were generated using the Search Tool for the Retrieval of Interacting Genes/Proteins (STRING) v11 (https://string-db.org/), using the significant proteins list after t-test analysis and setting a High Confidence value of 0.700 as a parameter. FDRs of Gene Ontology (GO) classification were calculated using STRING v11 for biological processes and performed as previously described by Szklarczyk et al (38). Biological processes were arbitrarily chosen so as not to overlap redundant classifications and obtain the largest number of classified targets. The FDR of GO and the P-value of the protein-protein interaction (PPI) enrichment were automatically calculated by STRING and the detailed description of the enrichment algorithm has been previously described (39).

Survival rates of patients with lung adenocarcinoma and lung squamous cell carcinoma were assessed using The Cancer Genome Atlas Pan-Lung Cancer database (40) (dbGaP Study Accession: phs000488.v1.p1) for ANXA4 and SOD2 in the cBioPortal software v3 5.0 (https://www.cbioportal.org/) (41). Each sample was defined as altered or unaltered for each gene based on the Onco Query Language, which considers non-synonymous mutations, fusions, amplifications and deep deletions (https://www.cbioportal.org/oql).

Statistical analysis. Statistical analyses were assessed using GraphPad Prism 8.01 software (GraphPad Software, Inc.) applying Student's unpaired t-test or one-way ANOVA followed by Tukey's post-hoc test when n sample was homogeneous between groups and Bonferroni's test when not meeting that condition. $\mathrm{P}<0.05$ was considered to indicate a statistically significant difference. For proteomics analysis, Student's t-tests were performed using Perseus.

\section{Results}

Metformin (MET) decreases cell viability and size without changes in the cell cycle. To demonstrate that $10 \mu \mathrm{M}$ cisplatin was able to create resistance in A549 cells, an MTT assay was performed to calculate the $\mathrm{IC}_{50}$. This cisplatin concentration was adopted since it had been previously reported to confer resistance to new cisplatin exposure in melanoma (42). A549 cells were subjected to $10 \mu \mathrm{M}$ cisplatin treatment for $72 \mathrm{~h}$ (called CIS population or CIS pop) and subsequent doses of cisplatin $(5,10,15,20,25,35$ and $50 \mu \mathrm{M})$ for another $72 \mathrm{~h}$. The CIS pop presented a significant increase in the $\mathrm{IC}_{50}$ compared with the untreated control population (Ctrl pop), suggesting the acquisition of resistance $(21.24 \mu \mathrm{M}$ for Ctrl pop vs. $32.86 \mu \mathrm{M}$ for CIS pop; Fig. 1A and B).

To investigate the effects of MET in lung cancer cells, MTT assay was performed (Fig. 2B) in the CIS pop compared with the Ctrl pop. MET decreased cell viability more extensively in the Ctrl pop (71.2\% for $24 \mathrm{~h}$ and $64.2 \%$ for $72 \mathrm{~h}$ exposure) compared with in the CIS pop (84.5\% for $24 \mathrm{~h}$ and $83.5 \%$ for 72 h) (Fig. 2B). Additionally, the viability of cells treated with MET was significantly decreased compared with that of cells treated with rapamycin (RAPA) in the Ctrl pop after $72 \mathrm{~h}(64.2$ vs. 95.5\%; Fig. 2B).

Cisplatin led to increased cell size and granularity, as seen by light microscopy and forward scatter and side scatter flow cytometry parameters (Fig. 2A and C, respectively), conferring more heterogeneity to the CIS pop compared with the Ctrl pop. In the CIS pop, flow cytometry data revealed that RAPA significantly decreased cell size after $24 \mathrm{~h}$, while MET significantly decreased cell size after $72 \mathrm{~h}$ treatment, both compared with cisplatin alone (Fig. 2D). However, only RAPA led to $\mathrm{G}_{0} / \mathrm{G}_{1}$ cell cycle arrest after $72 \mathrm{~h}$ treatment (Fig. 3A and B). The present data suggested that $72 \mathrm{~h}$ of MET treatment decreased cell viability and size in cisplatin-sensitive and -resistant cells without cell cycle impairment. In summary, MET decreased lung cancer cell viability and size without significantly changing the cell cycle.

MET reverts $m$ TOR activation induced by cisplatin in A549 cells. The mTOR signaling pathway status was evaluated by 


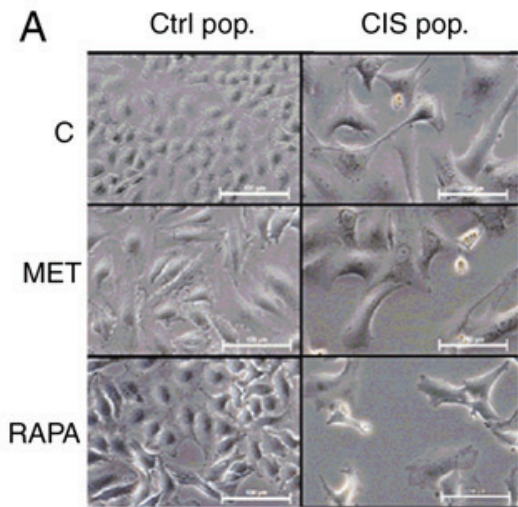

B

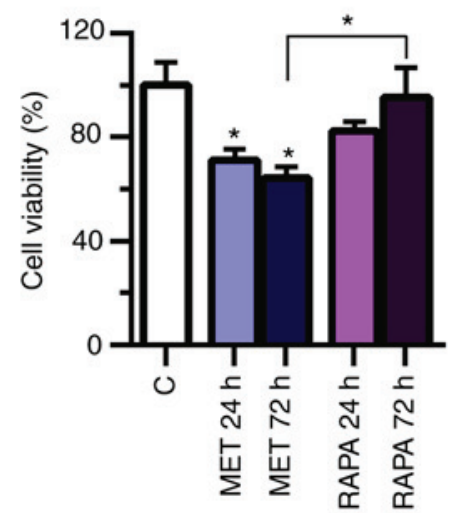

CIS pop.

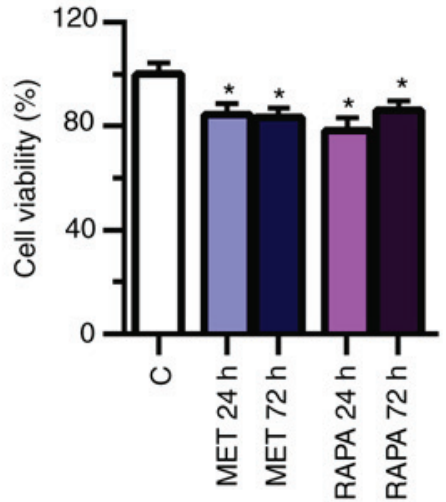

C

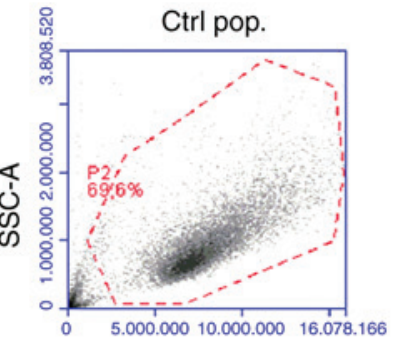

FSC-A
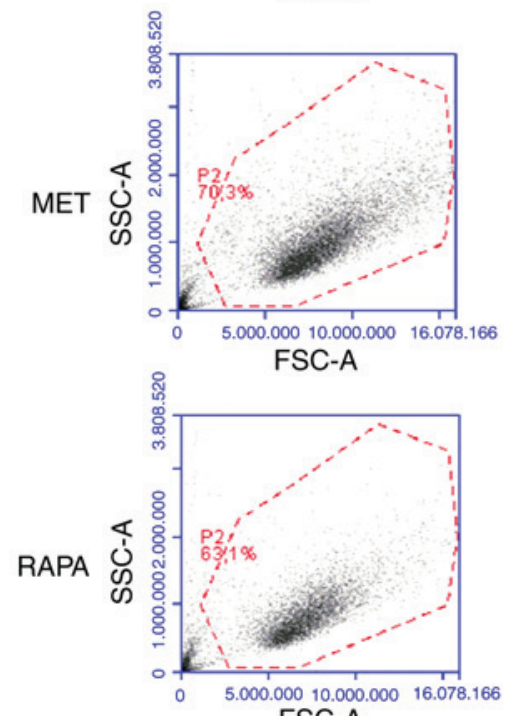

FSC-A

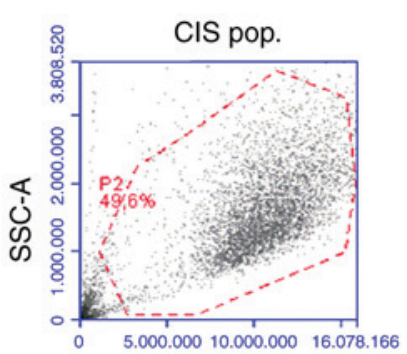

FSC-A
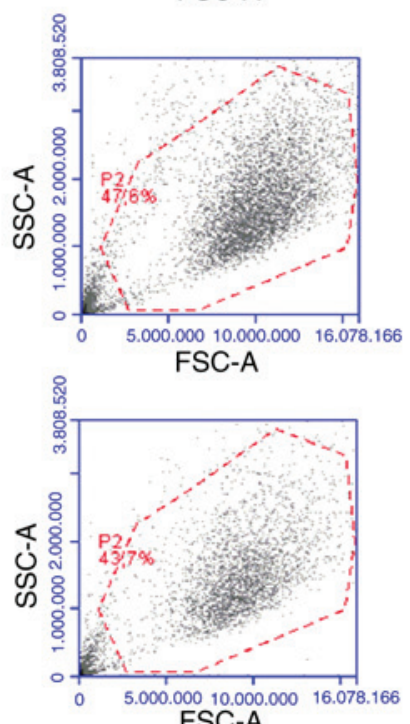

D
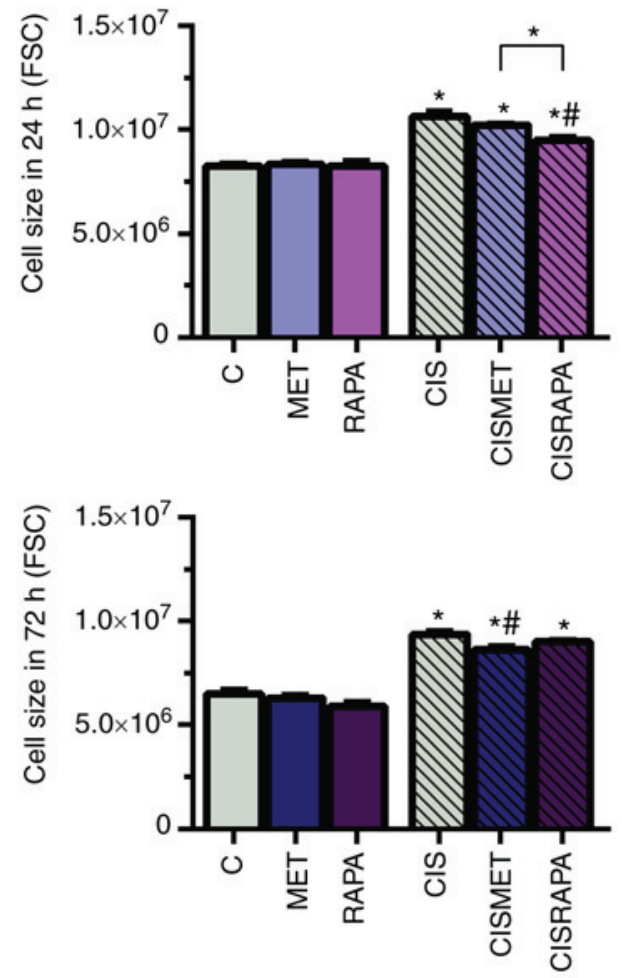

Figure 2. MET decreases cell viability and size in Ctrl and CIS-treated A549 cells. A549 cells exposed to $10 \mu \mathrm{M}$ CIS (CIS pop) or not (Ctrl pop) for $72 \mathrm{~h}$ were subsequently exposed to $10 \mathrm{mM}$ MET or $100 \mathrm{nM}$ RAPA for 24 and $72 \mathrm{~h}$. (A) Cell size increased in CIS-treated A549 cells and decreased in cells treated with $10 \mathrm{mM}$ MET or $100 \mathrm{nM}$ RAPA after $72 \mathrm{~h}$, as seen by microscopy. Scale bar, $100 \mu \mathrm{m}$. (B) MET and RAPA significantly decreased cell viability in the Ctrl and CIS pop after $72 \mathrm{~h}$. (C and D) CIS altered cell size after 24 and $72 \mathrm{~h}$, as analyzed by flow cytometry, and was then restored by MET after $72 \mathrm{~h}$ and by RAPA after 24 h. "P<0.05 vs. C; "P $<0.05$ vs. CIS. CIS, cisplatin; Ctrl/C, control; pop, population; MET, metformin; RAPA, rapamycin; FSC, forward scatter; SSC, side scatter.

western blotting after MET treatment in Ctrl and CIS pops. The analysis revealed that the mTOR signaling pathway was overactivated after cisplatin treatment, with a significant increase in S6K1 and S6 phosphorylation (Fig. 4A, D and E) compared with the control group. Subsequent MET treatment significantly decreased mTOR, S6K1 and S6 activation compared with CIS treatment, corroborating the aforementioned decreases in cell viability and size. A non-significant difference was observed in AMPK phosphorylation after MET treatment in A549 cells (Fig. 4C). The present results indicated robust activation of the mTOR signaling pathway after cisplatin treatment in A549 cells.

MET and RAPA decrease colony formation and sensitize A549 cells to cisplatin. To determine the colony formation potential of MET- and RAPA-treated cells, A549 cells exposed to $10 \mathrm{mM}$ MET or $100 \mathrm{nM}$ RAPA for 24 or $72 \mathrm{~h}$ were evaluated in a clonogenic cell assay (Fig. 5A). Compared with the control group, MET and RAPA treatments significantly decreased the absorbance of colonies formed (MET at $72 \mathrm{~h}$ and RAPA 

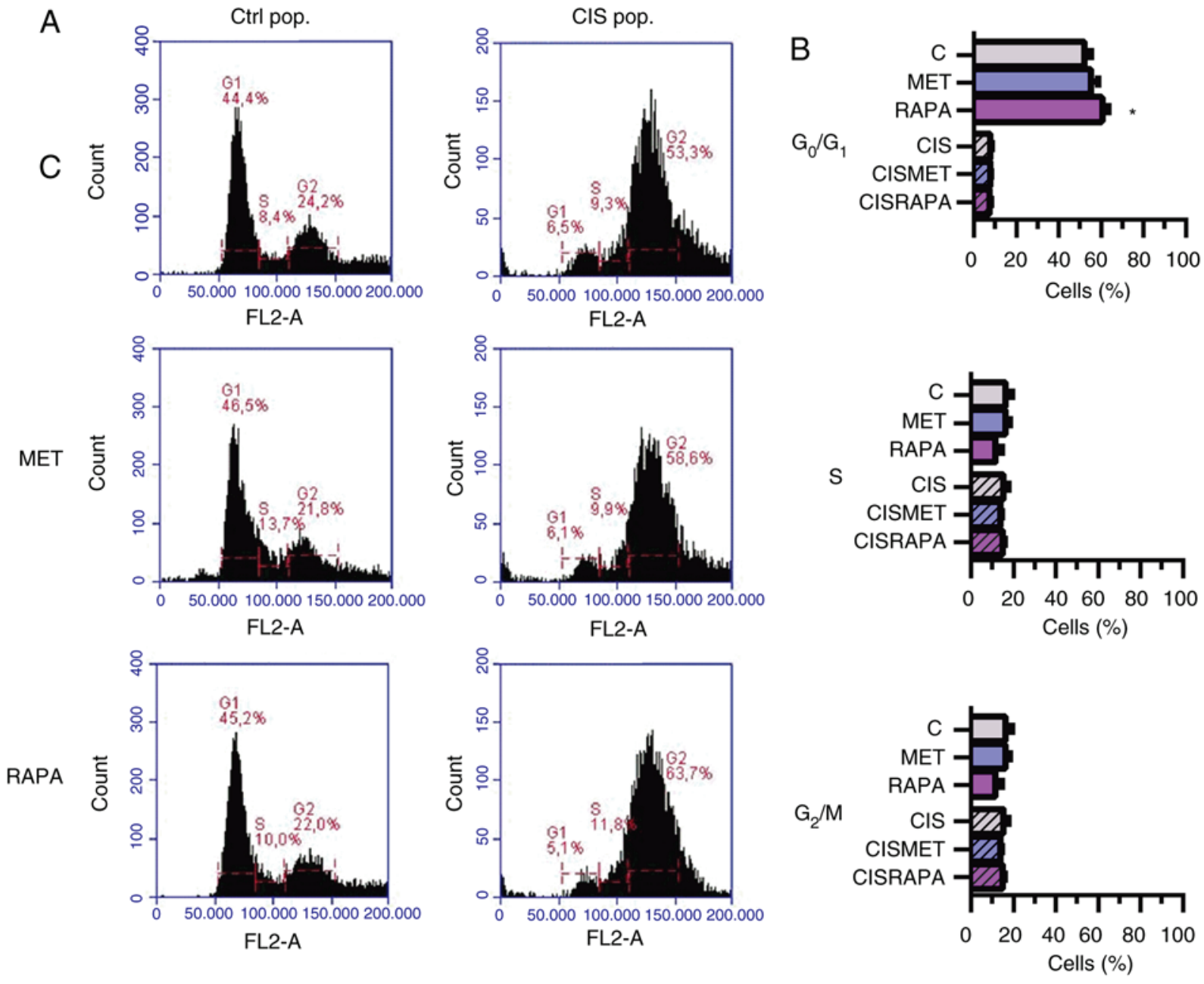

Figure 3. MET does not change the cell cycle in Ctrl and CIS-treated A549 cells. A549 cells exposed to $10 \mu \mathrm{M}$ CIS (CIS pop) or not (Ctrl pop) for $72 \mathrm{~h}$ were subsequently exposed to $10 \mathrm{mM}$ MET or $100 \mathrm{nM}$ RAPA for 24 and $72 \mathrm{~h}$. (A and B) Cell cycle was analyzed by flow cytometry in the Ctrl and CIS pop treated with MET and RAPA for $72 \mathrm{~h}$. "P<0.05 vs. C. CIS, cisplatin; Ctrl/C, control; pop, population; MET, metformin; RAPA, rapamycin.

at 24 and $72 \mathrm{~h}$ ) compared with the control group (Fig. 5B), but only RAPA decreased the size of colonies compared with the control group (Fig. 5C). Both MET and RAPA significantly decreased the $\mathrm{IC}_{50}$ in Ctrl pop cells $\left(\mathrm{IC}_{50}=15.4\right.$ and $14.5 \mu \mathrm{M}$, respectively, vs. $20.4 \mu \mathrm{M}$ for Ctrl; Fig. 5D and E). Thus, the decrease of $\mathrm{IC}_{50}$ indicated that previous treatment with MET or RAPA may potentiate and sensitize cells to cisplatin treatment.

Proteomics analysis reveals MET treatment profile in Ctrl and CIS populations. In addition to the mTOR signaling pathway, MET exerts important changes in crucial pathways involved in cancer (22). To investigate other possible molecular mechanisms involved in cisplatin sensitivity induced by MET, a proteomics analysis of A549 cells after MET treatment was performed, and the proteomes in control and cisplatin-resistant cells were compared using the SILAC approach (CxMET and CISxCISMET; Fig. 6A). A total of 903 proteins were quantified in CxMET and 646 in CISxCISMET, with 511 common proteins (Fig. 6B). The Student's t-test analysis indicated 361 differentially expressed and statistically significant proteins $(\mathrm{P}<0.05)$ for CxMET ratios and 254 for CISxCISMET ratios (Tables SI and SII). These proteins were classified and grouped based on their involvement in biological processes (Fig. 6C and D). GO terms and FDRs generated by STRING analysis are presented in Table I. PPI enrichment P-values were $<1.00^{-16}$ for CxMET and CISxCISMET networks (data not shown).

In the CxMET group, MET regulated 'viral process', 'mRNA metabolic process', 'IL-12 mediated signaling pathway', 'drug metabolic process', 'oxidation-reduction process', 'leukocyte degranulation', 'transport', 'regulation of cell death' and 'translation' (Fig. 6C). In the CISxCISMET group, MET regulated 'Golgi vesicle transport', 'protein folding', 'tRNA aminoacylation for protein translation', 'macromolecule catabolic process', 'oxidation-reduction process', 'leucocyte degranulation', 'mRNA metabolic process', 'viral process', 'regulation of cell death' and 'cytoskeleton organization' (Fig. 6D). The data revealed five shared pathways between groups ('mRNA metabolic process', 'oxidation-reduction process', 'leukocyte degranulation', 'viral process' and 'regulation of cell death'). The raw list of proteins identified by Perseus in both groups is presented in Tables SI and SII. Therefore, these molecular pathways may be potentially important signatures of the mechanisms of action of MET in lung cancer. 
A

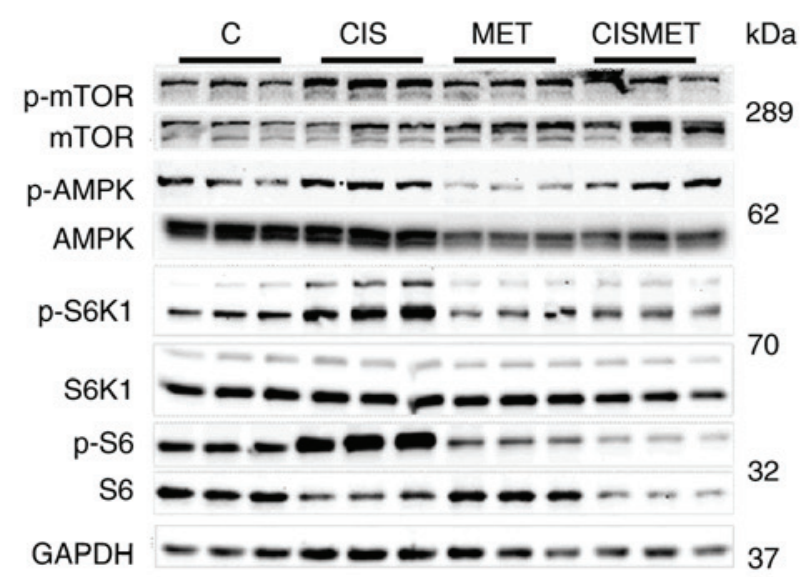

C

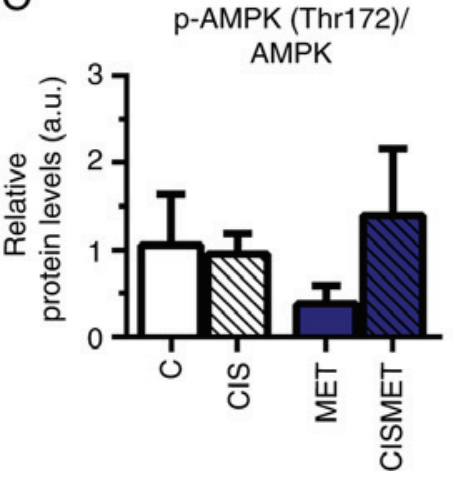

D

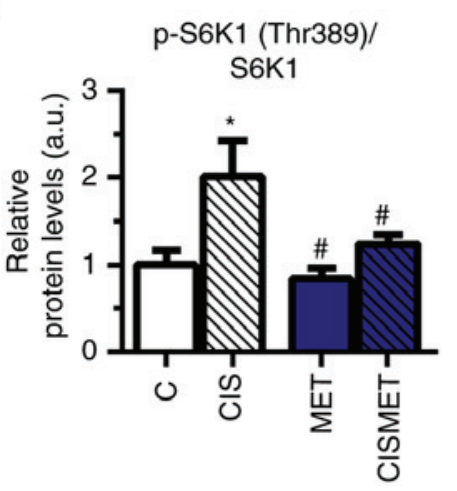

B

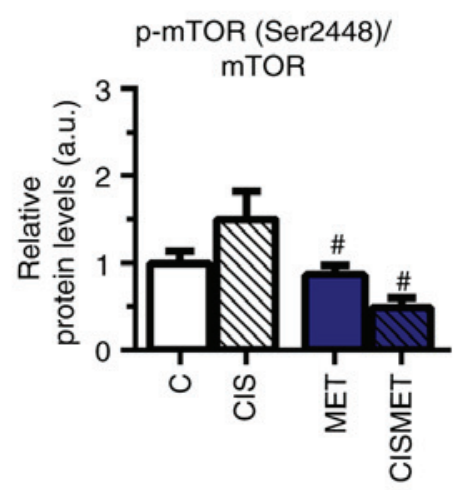

E

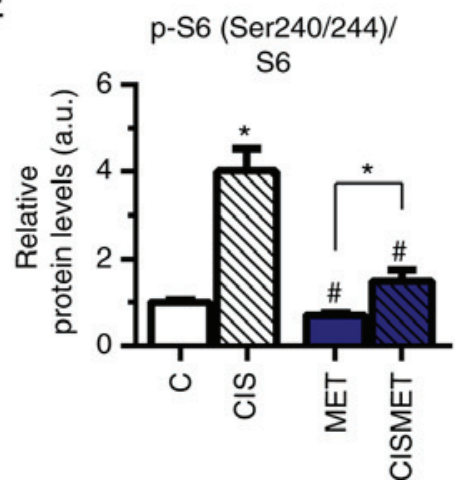

Figure 4. MET reverts mTOR activation induced by cisplatin in A549 lung cancer cells. (A) Analysis of protein content of the mTOR signaling pathway in A549 lung cancer cells after treatment with $10 \mu \mathrm{M}$ CIS for $72 \mathrm{~h}$ and $10 \mathrm{mM} \mathrm{MET}$ for $72 \mathrm{~h}$ analyzed via western blotting. Band densitometry performed using ImageJ of the protein expression levels of (B) p-mTOR/mTOR (n=2), (C) p-AMPK/AMPK (n=2), (D) p-S6K1/S6K1 (n=3) and (E) p-S6/S6 (n=3). * P<0.05 vs. C; ${ }^{\#} \mathrm{P}<0.05$ vs. CIS. CIS, cisplatin; C, control; MET, metformin; p, phosphorylated; a.u., arbitrary units.

MET alters translation, oxidative stress, apoptosis and metabolic pathways in control and cisplatin-resistant A549 cells. Volcano plots displayed the 1,448 proteins in CxMET and 1,158 in CISxCISMET (Fig. 7A), both separated by magnitude of evidence (P-value) and change (fold change of $\log 2$ ratio values) [cut-off values, $\log 10(0.05)=1.3010 ; \log 2$ ratio=1.00]. A total of 186 and 184 proteins were significantly downregulated and upregulated in MET compared with C, respectively, and 102 and 167 proteins were significantly downregulated and upregulated in CISMET compared with CIS, respectively. Applying the cut-off P-value, in CxMET the volcano plot expressed 3 significantly downregulated proteins, including ANXA4, and 12 significantly upregulated proteins, including SOD2. In CISxCISMET, the volcano plot expressed 7 significantly down-regulated proteins and 12 significantly upregulated proteins. Subsequently, 99 common significant proteins between CxMET and CISxCISMET analysis (ACADVL, ACTC1, ACTN1, ACTN4, AIFM1, AK3, AKR1C1, ALDH1A1, ALDH6A1, ANXA1, ANXA2, ANXA4, ARCN1, ARF3/ARF1, ARF4, C1orf57/NTPCR, CALD1, CALM2/CALM1, CANX, CCT8, CFL1, CPLX2, CRYAB, CS, CSRP1, CTSB, CTSD, DDX46, DYNC1H1, DYNC1LI2, ECH1, EIF4A1, EPRS, ETFA, ETFB, FARSB, FH, FKBP3, FLNA, G6PD, GAA, GAPDH, GCN1L1, GRPEL1, GSTP1, HADHA, HMGA1, HNRNPA2B1, HNRNPL, HSP90AA1, HSPA8, HSPD1, IARS, IGF2BP1, ILF2, ILF3, ITGB1, LARS, LDHA, LDHB, LRRFIP1, MARCKS, MDH2, MSN, MYH9,
NCL, NPC2, NPM1, PDHB, PGD, PKM2, PLOD2, PPIF, PTBP1, PTGR1, PYCR1, RAB2A/RAB2B, RPL19, RPL3, RPLP0, RPS17, SERPINE1, SF3A1, SLC39A7, SOD2, SRI, STIP1, SUB1, SUCLG2, TCP1, TGM2, TKT, TPM4, TRAP1, TUFM, UBC, UGDH, VCL and ZYX), altered after MET treatment and expressed by standardized values, were grouped in clusters by Euclidian distance using the average linkage in a heatmap (Fig. 7B). These proteins were then classified into two different networks, according to their upregulation or downregulation in resistant cells compared with control cells (Fig. 7C and Table I). Cisplatin resistance decreased proteins associated with 'transport' and 'mRNA metabolic process', while it upregulated proteins involved in 'translation' (Fig. 7C), corroborating the aforementioned activation of the mTOR signaling pathway. Regulation of 'oxidation-reduction process' and apoptotic processes were common biological processes found to be upregulated or downregulated by cisplatin treatment (Fig. 7C).

Two proteins reported by the proteomics analysis were chosen for further validation: ANXA4, involved in apoptosis (43), and SOD2, involved in oxidative stress pathways (44), which presented decreased and increased expression levels in the CIS versus CISMET analysis, respectively (Fig. 7D). The mRNA expression levels of these targets were further evaluated by RT-qPCR, revealing that MET significantly decreased ANXA4 expression compared with control, CIS and CISMET groups (Fig. 7E). Additionally, MET significantly increased 
A

C

MET

RAPA

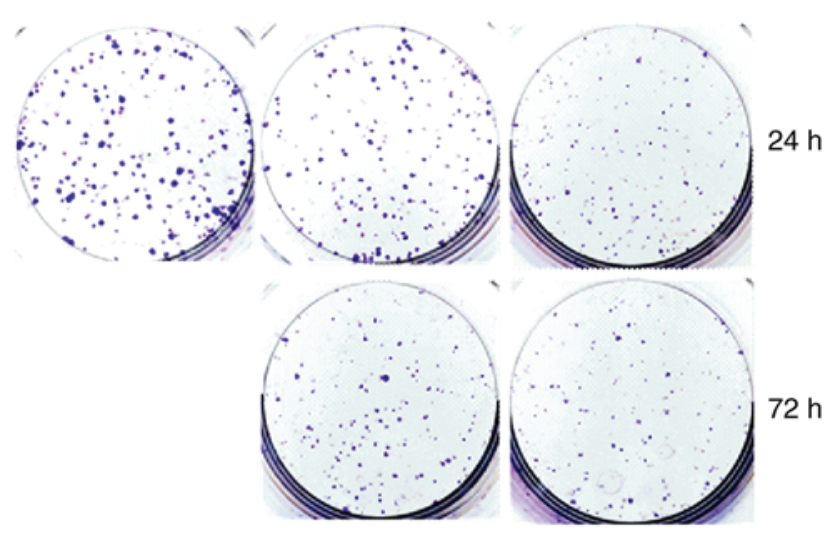

C

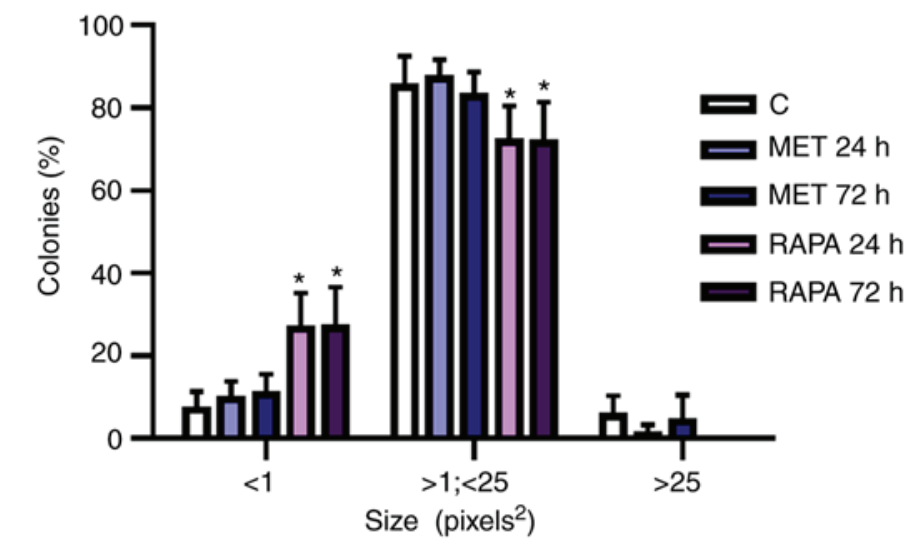

B

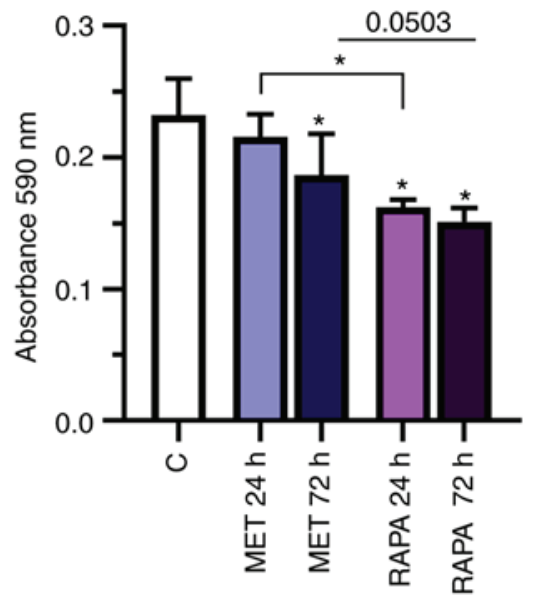

D

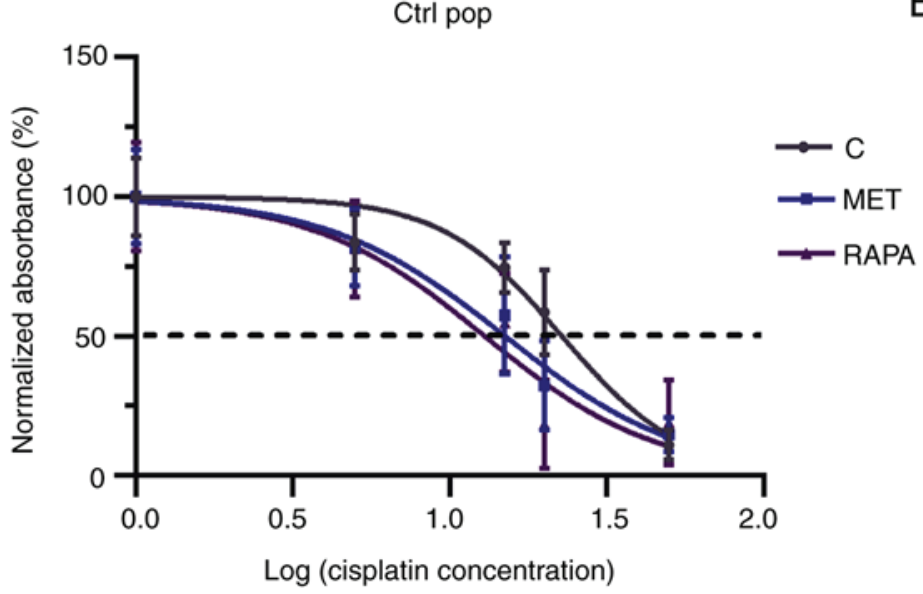

E

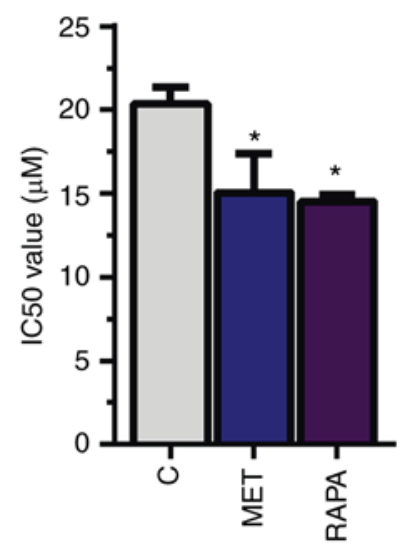

Figure 5. MET and RAPA decrease colony formation and $\mathrm{IC}_{50}$ in A549 lung cancer cells. (A) Ctrl pop cells were treated with $10 \mathrm{mM}$ MET or $100 \mathrm{nM}$ RAPA for 24 and $72 \mathrm{~h}$, and the clonogenic assay was performed. (B) Graph data presents the absorbance of crystal violet and (C) the size of colonies was measured using ImageJ. (D) Ctrl pop was treated with MET and RAPA, and subsequently subjected to CIS at different concentrations. (E) MET and RAPA pre-treatment in Ctrl pop followed by CIS treatment significantly decreased the $\mathrm{IC}_{50}$ values of CIS. "P<0.05 vs. C. CIS, cisplatin; Ctrl/C, control; pop, population; MET, metformin; RAPA, rapamycin.

SOD2 expression compared with control and CIS groups (Fig. 7E). Furthermore, treatment with MET in the Cis pop (CISMET group) significantly decreased ANXA4 expression and increased SOD2 expression compared with the CIS group (Fig. 7E). RT-qPCR data corroborated the proteomics analysis presented in the heatmap. A complementary analysis of the survival rates of patients with lung cancer using the cBioPortal revealed that alterations in the ANXA4 gene decreased the median survival time after initial treatment from 43.9 months to 19.5 months (Fig. S1). The altered group for SOD2 is represented by 10 patients (plus 2 deceased), with 5 patients with deep deletions of the gene (homodeleted) and 5 patients with missense mutations (G141C, L176R, R123H, G126A and S127F) (data not shown). The altered group for ANXA4 is represented by 12 patients (plus 5 deceased), with 8 patients with gene amplification and 4 patients with missense mutations (W188L, G33C, L316V and Q52E) (data not shown). Overall, MET decreased ANXA4 expression and increased 
A

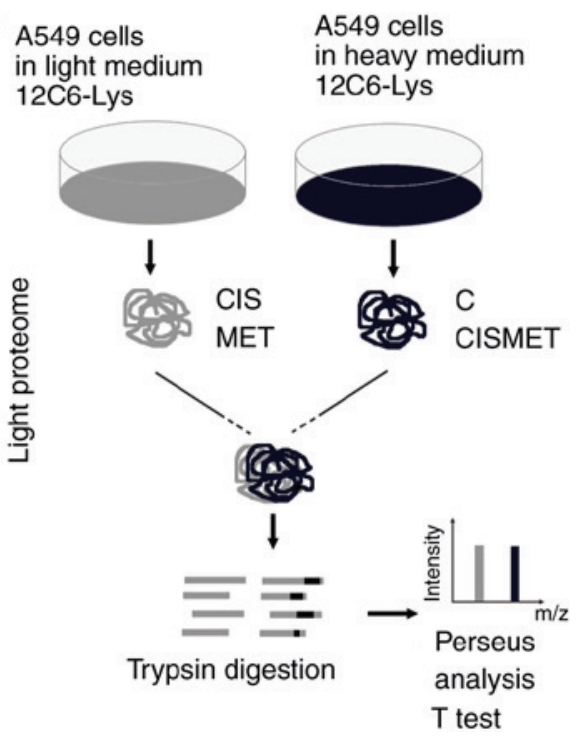

C

$\begin{aligned} \text { Color } & \text { Biological process (GO) } \\ 1 & \text { Viral process } \\ 2 & \text { mRNA metabolic process } \\ 3 & \text { Shared pathways } \\ 4 & \text { IL-12 mediated signaling pathway } \\ 5 & \text { Others } \\ 6 & \text { Drug metabolic process } \\ 7 & \text { Oxidation-reduction process } \\ 8 & \text { Leukocyte degranulation } \\ 9 & \text { Transport } \\ 10 & \text { Regulation of cell death } \\ 11 & \text { Translation }\end{aligned}$

D

$\begin{array}{ll}\text { Color } & \text { Biological process (GO) } \\ 1 & \text { Shared pathways } \\ 2 & \text { Golgi vesicle transport } \\ 3 & \text { Protein folding } \\ 4 & \text { tRNA aminoacylation for protein translation } \\ 5 & \text { Macromolecule catabolic process } \\ 6 & \text { Oxidation-reduction process } \\ 7 & \text { Leukocyte degranulation } \\ 8 & \text { Others } \\ 9 & \text { mRNA metabolic process } \\ 10 & \text { Viral process } \\ 11 & \text { Regulation of cell death } \\ 12 & \text { Cytoskeleton organization }\end{array}$

B CXMET_1 CXMET_2 CISxCISMET_1 CISxCISMET_2

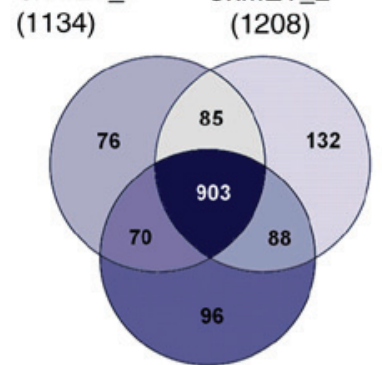

(803)

(967)

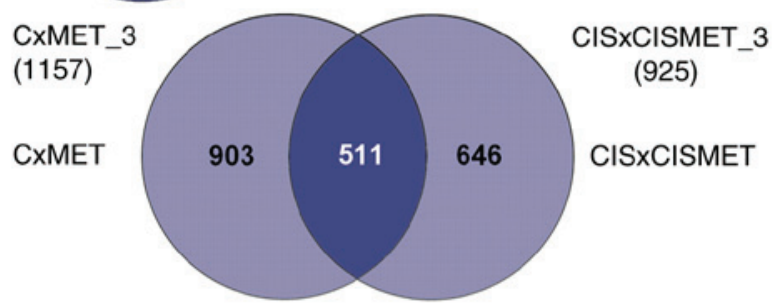

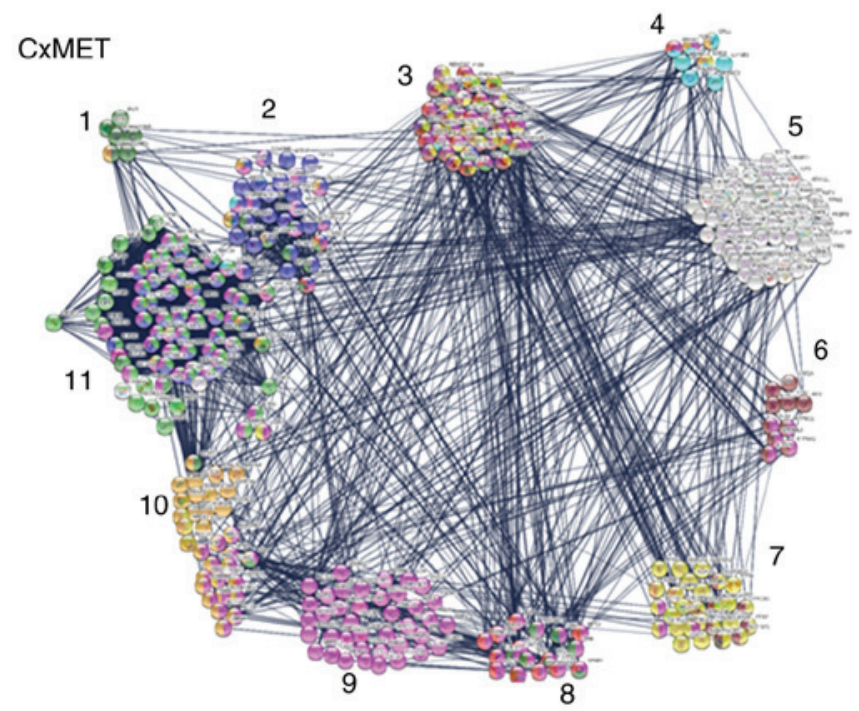

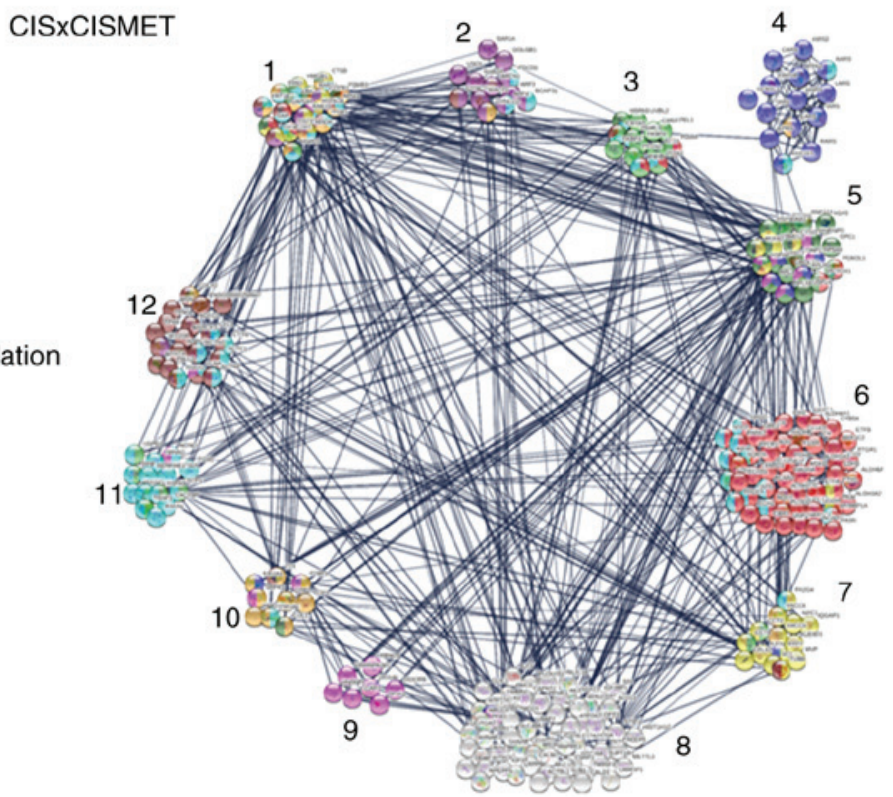

Figure 6. Proteomics analysis reveals modulated pathways after MET treatment in control and CIS-resistant A549 cells. (A) Experimental design of proteomics analysis using the Stable Isotope Labeling by Amino acids in Cell culture approach. (B) Venn diagrams presenting 903 proteins detected in control (CxMET) and 646 proteins in CIS-resistant cells (CISxCISMET), as well as 511 common proteins in both groups. Network analysis performed using the Search Tool for the Retrieval of Interacting Genes/Proteins revealing (C) 361 proteins in CxMET and (D) 254 proteins in CISxCISMET separated according to GO biological processes. CIS, cisplatin; MET, metformin; GO, Gene Ontology. 
Table I. Biological processes, GO numbers and FDRs associated with each proteomic network.

\begin{tabular}{|c|c|c|c|c|c|}
\hline Biological processes & GO no. & CXMET & CISXCISMET & Upregulated & Downregulated \\
\hline Viral process & 0016032 & $8.62 \times 10^{11}$ & $6.97 \times 10^{07}$ & - & - \\
\hline Regulation of mRNA metabolic process & 1903311 & - & - & - & 0.0283 \\
\hline mRNA metabolic process & 0016071 & $3.57 \times 10^{35}$ & 0.0076 & - & - \\
\hline IL-12 mediated signaling pathway & 0035722 & $1.94 \times 10^{07}$ & - & - & 0.0019 \\
\hline Translation & 0006412 & $2.30 \times 10^{42}$ & $2.83 \times 10^{07}$ & $6.65 \times 10^{05}$ & - \\
\hline Regulation of cell death & 0010941 & $3.78 \times 10^{07}$ & $3.02 \times 10^{09}$ & - & - \\
\hline Transport & 0006810 & $8.36 \times 10^{27}$ & - & - & 0.0290 \\
\hline Leukocyte degranulation & 0043299 & $4.18 \times 10^{06}$ & $5.24 \times 10^{10}$ & - & - \\
\hline Oxidation-reduction process & 0055114 & $4.55 \times 10^{15}$ & $1.76 \times 10^{20}$ & $9.19 \times 10^{06}$ & 0.0021 \\
\hline Drug metabolic process & 0017144 & $3.11 \times 10^{13}$ & - & - & - \\
\hline Golgi vesicle transport & 0048193 & - & $6.64 \times 10^{05}$ & - & - \\
\hline Protein folding & 0006457 & - & $3.41 \times 10^{13}$ & 0.00014 & - \\
\hline Macromolecule catabolic process & 0009057 & - & 0.00032 & - & - \\
\hline Cytoskeleton organization & 0007010 & - & 0.00055 & - & - \\
\hline Negative regulation of apoptotic process & 0043066 & - & - & - & 0.0019 \\
\hline Regulated exocitosis & 0045055 & - & - & $4.45 \times 10^{06}$ & - \\
\hline Regulation of apoptotic process/apoptosis & 0042981 & - & - & 0.0048 & - \\
\hline
\end{tabular}

GO, Gene Ontology; FDR, false discovery rate; CIS, cisplatin; MET, metformin.

SOD2 expression in A549 cells, validating the presented proteomics data.

\section{Discussion}

Over the last years, MET has been widely used as an antidiabetic agent and has been characterized to present antitumor properties and several advantages in cancer therapy (45). The mechanisms by which MET decreases tumor progression and presents chemosensitivity abilities are not fully described, but it seems that AMPK-driven inhibition of mTOR is an important regulating axis in the tumorigenic process (22). The mTOR signaling pathway is also described as a pathway with implications in tumor development and progression, metastasis and chemoresistance (46). The present study indicated that MET may potentially affect lung cancer progression and cisplatin chemosensitivity, and may be associated with mTOR signaling and other pathways, such as translation, oxidative stress and apoptosis.

In the present study, MET decreased the viability in Ctrl and cisplatin-treated cells, as described in breast $(47,48)$, ovarian (49) and lung cancer cell lines (50). Stronger effects of MET on viability may be possible due to its extensive and embracing mechanisms of action compared with the point target effects of RAPA, as previously reported in pancreatic cancer cells (51). Although other studies have reported cell cycle arrest after MET treatment in different cell lines (52-54), no changes were observed in the present study in the A549 cell cycle. However, it was confirmed that cisplatin led to cell cycle arrest in the $\mathrm{G}_{2} / \mathrm{M}$ phase, which is a characteristic of platinum drugs (55), and that RAPA led to $G_{0} / G_{1}$ arrest, which has been also previously reported (56-58). Additionally, the current study indicated that MET reverted the increase in cell size induced by cisplatin after $72 \mathrm{~h}$, which was consistent with decreased mTOR signaling. Wang et al (59) reported that cell cycle arrest induced by MET in myeloma is dependent on the mTOR signaling pathway, possibly via intact LKB1-AMPK axis also observed in A549 cells (60). mTOR inhibition seems to be an important strategy to improve cisplatin sensitivity, mediating the chemotherapy resistance in KRAS-mutant lung cancer (31). Several studies have demonstrated that cisplatin resistance induces activation of the mTOR/Akt signaling pathway and decreases apoptosis, whereas inhibitors of the mTOR/Akt signaling pathway sensitize and enhance the effects of cisplatin in different cancer cell lines, including lung cancer (61) and hepatocarcinoma cells (62). In esophageal squamous cell carcinoma (ESCC) xenografts, a small interfering RNA against mTOR significantly increased apoptosis when combined with cisplatin (63). Moreover, patients with endometrial cancer treated with MET presented decreased levels of plasma IGF-1 and PI3K, phospho-Akt, phospho-S6K1 and phospho-4EBP1 in biopsy specimens, reinforcing its antiproliferative potential (64). In accordance with the aforementioned studies, the present study confirmed in vitro that MET decreases cell viability and clonogenic potential, sensitizes cells to cisplatin by decreasing the $\mathrm{IC}_{50}$ and is associated with decreased mTOR signaling, indicating that MET may be a potential coadjuvant in NSCLC therapy.

Galluzzi et al $(65,66)$ defined mechanisms of cisplatin resistance and its associated targets in different signaling pathways. Cisplatin resistance is generally multifactorial, characterized by successive molecular alterations, including the binding of cisplatin to its targets, increased repair mechanisms, decreased apoptosis and stimulation of pro-survival mechanisms $(67,68)$. Considering cisplatin resistance and tumor progression, it is important to target more than one 
A

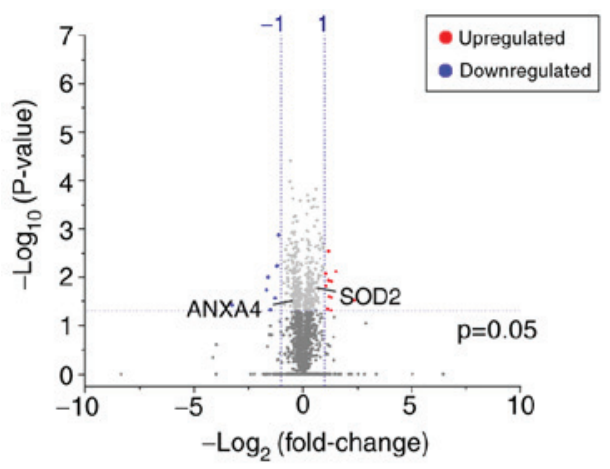

C

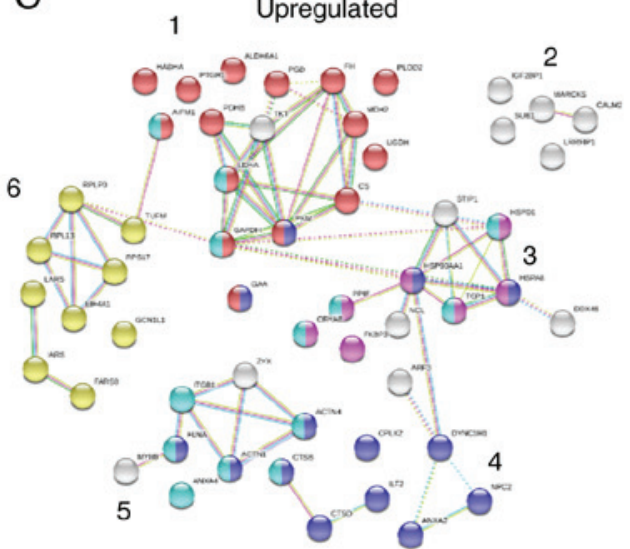

Color Biological process (GO)

1 Oxidation-reduction process

2 Others

$3 \bigcirc$ Protein folding

$4 \bigcirc$ Regulated exocitosis

$5 \bigcirc$ Apoptosis

6 Translation
CISxCISMET

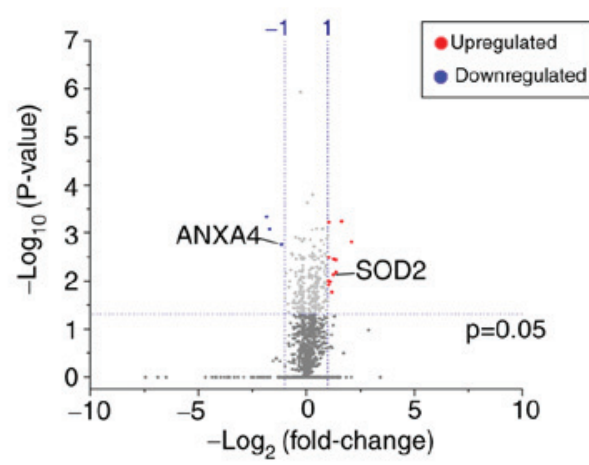

Downregulated

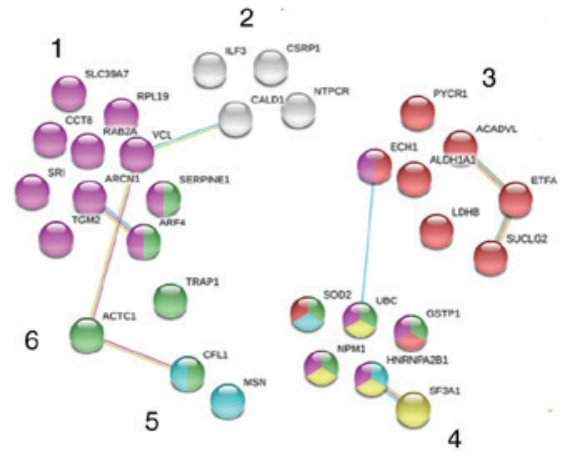

Color Biological process (GO)

1 Transport

2 Others

3 Oxidation-reduction process

4 mRNA metabolic process

5 IL-12 mediated signaling pathway

6 Negative regulation of apoptosis
D

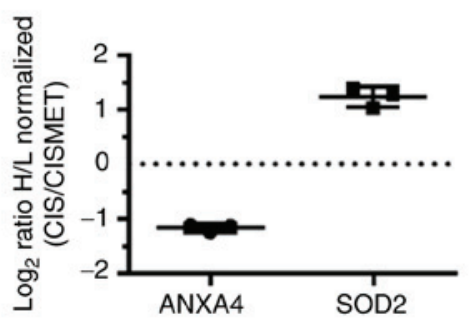

E

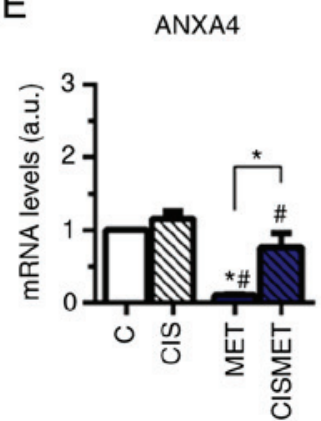

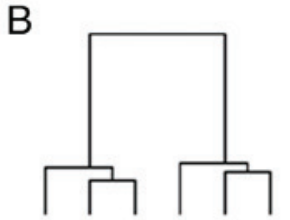
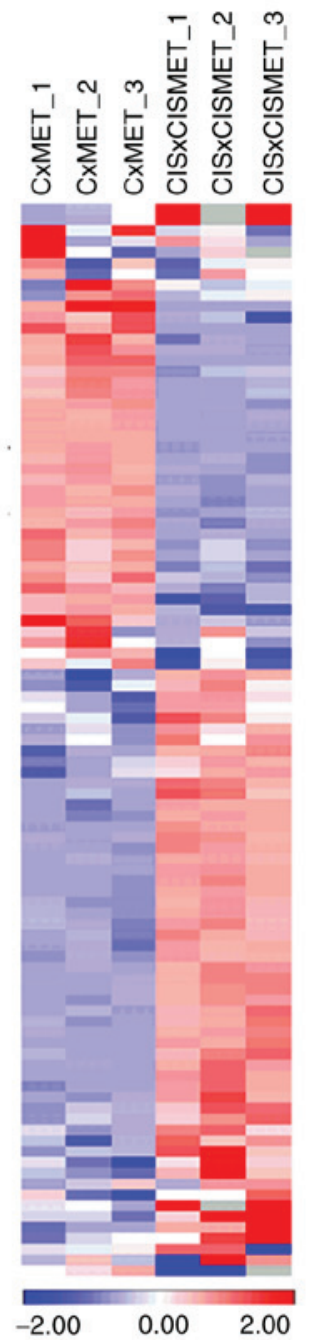

Figure 7. Proteomics analysis revealing upregulated and downregulated targets after MET treatment in control and CIS-resistant A549 cells. (A) Volcano

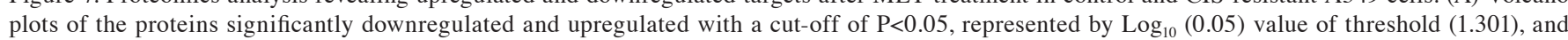
normalized H/L ratio $> \pm 1$ for both groups. (B) Heatmap of the common significant proteins with $\mathrm{P}<0.05$. (C) Upregulated and downregulated proteins in CISxCISMET compared with CxMET were classified using the Search Tool for the Retrieval of Interacting Genes/Proteins according to GO biological processes. (D) Normalized H/L ratios of two selected proteins from the proteomics analysis, SOD2 and ANXA4. (E) Reverse transcription-quantitative PCR reported altered expression levels of ANXA4 and SOD2 after MET treatment. " $\mathrm{P}<0.05$ vs. C; ${ }^{\mathrm{P}}<0.05$ vs. CIS. CIS, cisplatin; C, control; MET, metformin; GO, Gene Ontology; ANXA4, annexin 4; SOD2, superoxide dismutase 2; H/L, heavy to light ratio; a.u., arbitrary units.

molecular mechanism to efficiently circumvent cisplatin resistance $(65,66)$.

Understanding the MET-induced proteomic changes in sensitive and resistant contexts provides important information about specific modifications acquired by cells (67).
Regarding the multifactorial resistance profile, the present study aimed to investigate other potential signaling pathways involved in cisplatin sensitivity induced by MET in addition to mTOR signaling. In both sensitive and resistant cells, MET altered transcriptional processes, regulated apoptosis, 
oxidation-reduction processes and proteins associated with leukocyte degranulation, with 99 common significantly altered targets, of which some have been previously described: AK3 (68), ALDH1A1 (69), ANXA2 and 4 (70,71), CFL1 (72), CRYAB (73), filamin A (FLNA) (74), GSTP1 (75), HMGA1 and G6PD (76), hnRNPA2B1 (77), HSP90 (78), IGF2BP1 (79), integrin b1 (ITGB1) (80), MYH9 (81), PKM2 (82-84), STIP1 (85), TGM2 (86), TKT (87) and TRAP1 (88).

In the present study, comparing sensitive and resistant contexts, MET decreased several oncogenes, such as CD29, FLNA, CTSD, MSN and ANXA4. Despite IL-12-mediated signaling having been associated with antitumor effects (89), the pathway component MSN has been largely associated with tumor progression (90-92). The present proteomic analysis revealed that MET increased apoptosis in cisplatin-resistant cells, as previously reported $(33,53,93)$, by decreasing anti-apoptotic proteins such as TRAP1, CFL1 and SOD2. On the other hand, potential tumor progressors, such as CD29, cathepsin D (CTSD), FLNA and ANXA4, were upregulated. CD29, also known as ITGB1, is a transmembrane cell surface receptor that has been associated with metastasis, tumor migration and drug resistance $(94,95)$. ITGB1 is associated with resistance to gefitinib in NSCLC (96) and its knockdown overcomes erlotinib resistance in lung cancer cells and decreases the activation of Akt after erlotinib treatment (97). FLNA acts as a scaffold for cancer-associated signaling pathways and is associated with the aggressive pattern and poor survival outcomes in patients with NSCLC treated with platinum-based drugs, such as cisplatin (98). Furthermore, FLNA may interact with other oncogenes, such as Akt, K-RAS, TRAF2, NIK and 14-3-3o (99-102). CTSD is an intracellular aspartic protease of the pepsin superfamily associated with inhibition of SERPINE1 and is a tumor marker for invasion and metastasis $(103,104)$. Overexpression of CTSD promotes breast cancer cell migration, invasion and metastasis through intercellular cell adhesion molecule-1 both in vitro and in vivo (105).

For the validation of the proteomics analysis, two targets were chosen, SOD2 (upregulated) and ANXA4 (downregulated), whose roles in cisplatin resistance are already known and well-documented. SOD2, a superoxide scavenger, may be directly involved in carcinogenesis by protecting cells against increased levels of reactive oxygen species (ROS) (106). It has been previously described that SOD2 can protect against DNA damage-inducing agents, especially in radiation (107-109). ROS act as mediators of DNA damage and SOD2, an endogenous antioxidant, protects the cells from DNA damage by scavenging reactive molecules, such as superoxide (110). One of the mechanisms described for the action of cisplatin is the depletion of antioxidant molecules to tilt the redox balance towards oxidative stress, which facilitates DNA damage (65). Additionally, cisplatin treatment increases ROS content in human lung cancer cells, including A549 cells (111). On the other hand, the overexpression of SOD2 in mitochondria enhance the survival of HeLa cells and contribute to cisplatin resistance in human ESCC and oral squamous cell carcinoma cell lines $(110,112)$.

ANXA4 is largely involved in the proliferation, platinum resistance and migration in different types of cancer cells, such as ovarian $(43,113)$ and endometrial cancer cells (114).
ANXA4 overexpression is associated with tumor cell invasion and poor prognosis in patients with gallbladder cancer (115). Furthermore, overexpression of ANXA4 confers carboplatin resistance in ovarian carcinoma cells (114). ANXA4-knockdown increases sensitivity to platinum-based drugs both in vitro and in vivo $(70,116)$ and the gain of its expression can restore cisplatin resistance in mesothelioma cells (116), which reinforces the beneficial effects of MET in decreasing ANXA4 expression. According to the present survival analysis, alterations in ANXA4 may decrease patient survival. Since treatment with MET significantly decreased ANXA4 expression, ANXA4 may be explored as a potential marker for survival and cisplatin responsiveness in lung cancer.

In conclusion, the present study demonstrated that MET sensitized cells to cisplatin treatment and decreased clonogenic survival and viability in A549 lung cancer cells. The mTOR signaling pathway was overactivated after cisplatin treatment, which was restored by MET regardless of the LKB1-AMPK axis. Therefore, MET may be able to improve the chemotherapeutic effects of cisplatin in A549 cells by decreasing mTOR signaling and modulating apoptosis, translation-associated processes and oxidative pathways, thus providing potential new therapeutic targets to circumvent cisplatin resistance in NSCLC.

\section{Acknowledgements}

The authors would like to acknowledge the Mass Spectrometry Laboratory at Brazilian Biosciences National Laboratory (Campinas, Brazil) for their support with mass spectrometry analysis.

\section{Funding}

The present study was funded by the São Paulo Research Foundation (FAPESP; grant nos. 2012/13558-7, 2018/14818-9, 2016/06457-0 and 2015/22814-5; fellowship nos. 2016/02483-7, 2017/04269-5, 2019/00607-9, 2015/003111 and 2015/16601-9) and by the National Council for Scientific and Technological Development (grant no. 447553/2014-3).

\section{Availability of data and materials}

The datasets used and/or analyzed during the current study are available from the corresponding author on reasonable request. Additionally, the proteomic datasets generated and/or analyzed during the current study are available in the PRIDE repository (https://www.ebi.ac.uk/pride/). The mass spectrometry proteomics data have been deposited in the ProteomeXchange Consortium (http://proteomecentral. proteomexchange.org) via the PRIDE partner repository (117) with the dataset identifier PXD017645 (https://www.ebi. ac.uk/pride/archive/projectPXD017645).

\section{Authors' contributions}

APM, ICBP and FRS performed the cell experiments and revised the manuscript. APM, ICBP, AFPL, DCG, BAP and RRD performed mass spectrometry experiments and proteomics data analysis. GFP performed bioinformatics 
analysis. APM wrote the manuscript and headed the execution of all experiments. APM, FMS, RMNB, TCT, LPDM, DCG, AFPL and RC designed the experiments and revised the manuscript. APM and FMS confirmed the authenticity of the raw data. All authors read and approved the final manuscript.

\section{Ethics approval and consent to participate}

Not applicable.

\section{Patient consent for publication}

Not applicable.

\section{Competing interests}

The authors declare that they have no competing interests.

\section{References}

1. Bray F, Ferlay J, Soerjomataram I, Siegel RL, Torre LA and Jemal A: Global cancer statistics 2018: GLOBOCAN estimates of incidence and mortality worldwide for 36 cancers in 185 countries. CA Cancer J Clin 68: 394-424, 2018

2. Ridge CA, McErlean AM and Ginsberg MS: Epidemiology of lung cancer. Semin Intervent Radiol 30: 93-98, 2013.

3. Hirsch FR, Scagliotti GV, Mulshine JL, Kwon R, Curran WJ, Wu YL and Paz-Ares L: Lung cancer: Current therapies and new targeted treatments. Lancet 389: 299-311, 2017.

4. Talebian Yazdi M, Schinkelshoek MS, Loof NM, Taube C, Hiemstra PS, Welters MJ and van der Burg SH: Standard radiotherapy but not chemotherapy impairs systemic immunity in non-small cell lung cancer. Oncoimmunology 5: e1255393, 2016.

5. Sarin N, Engel F, Kalayda GV, Mannewitz M, Cinatl J Jr, Rothweiler F, Michaelis M, Saafan H, Ritter CA, Jaehde U and Frötschl R: Cisplatin resistance in non-small cell lung cancer cells is associated with an abrogation of cisplatin-induced G2/M cell cycle arrest. PLoS One 12: e0181081, 2017.

6. Yang Z, Hackshaw A, Feng Q, Fu X, Zhang Y, Mao C and Tang J: Comparison of gefitinib, erlotinib and afatinib in non-small cell lung cancer: A meta-analysis. Int J Cancer 140: 2805-2819, 2017.

7. Garon EB, Rizvi NA, Hui R, Leighl N, Balmanoukian AS Eder JP, Patnaik A, Aggarwal C, Gubens M, Horn L, et al: Pembrolizumab for the treatment of non-small-cell lung cancer. N Engl J Med 372: 2018-228, 2015.

8. Uchibori K, Inase N, Araki M, Kamada M, Sato S, Okuno Y, Fujita N and Katayama R: Brigatinib combined with anti-EGFR antibody overcomes osimertinib resistance in EGFR-mutated non-small-cell lung cancer. Nat Commun 8: 14768, 2017.

9. Facchinetti F, Rossi G, Bria E, Soria JC, Besse B, Minari R, Friboulet $\mathrm{L}$ and Tiseo M: Oncogene addiction in non-small cell lung cancer: Focus on ROS1 inhibition. Cancer Treat Rev 55: 83-95, 2017.

10. Planchard D, Kim TM, Mazieres J, Quoix E, Riely G, Barlesi F, Souquet PJ, Smit EF, Groen HJ, Kelly RJ, et al: Dabrafenib in patients with BRAF(V600E)-positive advanced non-small-cell lung cancer: A single-arm, multicentre, open-label, phase 2 trial. Lancet Oncol 17: 642-650, 2016.

11. Herbst RS, Morgensztern D and Boshoff C: The biology and management of non-small cell lung cancer. Nature 553: 446-454, 2018.

12. Decensi A, Puntoni M, Goodwin P, Cazzaniga M, Gennari A, Bonanni B and Gandini S: Metformin and cancer risk in diabetic patients: A systematic review and meta-analysis. Cancer Prev Res (Phila) 3: 1451-1461, 2010.

13. Cantrell LA, Zhou C, Mendivil A, Malloy KM, Gehrig PA and Bae-Jump VL: Metformin is a potent inhibitor of endometrial cancer cell proliferation-implications for a novel treatment strategy. Gynecol Oncol 116: 92-98, 2010.

14. Dong L, Zhou Q, Zhang Z, Zhu Y, Duan T and Feng Y: Metformin sensitizes endometrial cancer cells to chemotherapy by repressing glyoxalase I expression. J Obstet Gynaecol Res 38: 1077-1085, 2012.
15. Duo J, Ma Y, Wang G, Han X and Zhang C: Metformin synergistically enhances antitumor activity of histone deacetylase inhibitor trichostatin a against osteosarcoma cell line. DNA Cell Biol 32: 156-164, 2013.

16. Fujita H, Hirose K, Sato M, Fujioka I, Fujita T, Aoki M and Takai Y: Metformin attenuates hypoxia-induced resistance to cisplatin in the HepG2 cell line. Oncol Lett 17: 2431-2440, 2018.

17. Lin CC, Yeh HH, Huang WL, Yan JJ, Lai WW, Su WP, Chen HH and Su WC: Metformin enhances cisplatin cytotoxicity by suppressing signal transducer and activator of transcription-3 activity independently of the liver kinase B1-AMP-activated protein kinase pathway. Am J Respir Cell Mol Biol 49: 241-250, 2013.

18. Yu G, Fang W, Xia T, Chen Y, Gao Y, Jiao X, Huang S, Wang J, $\mathrm{Li} \mathrm{Z}$ and Xie K: Metformin potentiates rapamycin and cisplatin in gastric cancer in mice. Oncotarget 6: 12748-1262, 2015.

19. Teixeira SF, Guimarães I dos S, Madeira KP, Daltoé RD, Silva IV and Rangel LB: Metformin synergistically enhances antiproliferative effects of cisplatin and etoposide in NCI-H460 human lung cancer cells. J Bras Pneumol 39: 644-649, 2013

20. Li L, Han R, Xiao H, Lin C, Wang Y, Liu H, Li K, Chen H, Sun F, Yang Z, Jiang $\mathrm{J}$ and $\mathrm{He} \mathrm{Y}$ : Metformin sensitizes EGFR-TKI-resistant human lung cancer cells in vitro and in vivo through inhibition of IL-6 signaling and EMT reversal. Clin Cancer Res 20: 2714-2726, 2014.

21. Li L, Wang Y, Peng T, Zhang K, Lin C, Han R, Lu C and He Y: Metformin restores crizotinib sensitivity in crizotinib-resistant human lung cancer cells through inhibition of IGF1-R signaling pathway. Oncotarget 7: 34442-34452, 2016.

22. Pernicova I and Korbonits M: Metformin-mode of action and clinical implications for diabetes and cancer. Nat Rev Endocrinol 10: 143-156, 2014.

23. Liu GY and Sabatini DM: mTOR at the nexus of nutrition, growth, ageing and disease. Nat Rev Mol Cell Biol 21: 183-203, 2020

24. Tavares MR, Pavan IC, Amaral CL, Meneguello L, Luchessi AD and Simabuco FM: The S6K protein family in health and disease. Life Sci 131: 1-10, 2015.

25. Magnuson B, Ekim B and Fingar DC: Regulation and function of ribosomal protein S6 kinase (S6K) within mTOR signalling networks. Biochem J 441: 1-21, 2012.

26. Amaral CL, Freitas LB, Tamura RE, Tavares MR, Pavan IC, Bajgelman MC and Simabuco FM: S6Ks isoforms contribute to viability, migration, docetaxel resistance and tumor formation of prostate cancer cells. BMC Cancer 16: 602, 2016.

27. Zhong D, Guo L, de Aguirre I, Liu X, Lamb N, Sun SY, Gal AA, Vertino PM and Zhou W: LKB1 mutation in large cell carcinoma of the lung. Lung Cancer 53: 285-294, 2006.

28. Kullmann L and Krahn MP: Controlling the master-upstream regulation of the tumor suppressor LKB1. Oncogene 37: 3045-3057, 2018

29. Jiang G and Liu CT: Knockdown of SALL4 overcomes cisplatin-resistance through AKT/mTOR signaling in lung cancer cells. Int J Clin Exp Pathol 11: 634-641, 2018.

30. Teng X, Fan XF, Li Q, Liu S, Wu DY, Wang SY, Shi Y and Dong M: XPC inhibition rescues cisplatin resistance via the Akt/mTOR signaling pathway in A549/DDP lung adenocarcinoma cells. Oncol Rep 41: 1875-1882, 2019.

31. Liang SQ, Bührer ED, Berezowska S, Marti TM, Xu D, Froment L, Yang H, Hall SRR, Vassella E, Yang Z, et al: mTOR mediates a mechanism of resistance to chemotherapy and defines a rational combination strategy to treat KRAS-mutant lung cancer. Oncogene 38: 622-636, 2019.

32. Algire C, Amrein L, Bazile M, David S, Zakikhani M and Pollak M: Diet and tumor LKB1 expression interact to determine sensitivity to anti-neoplastic effects of metformin in vivo. Oncogene 30: 1174-1182, 2011

33. Moro M, Caiola E, Ganzinelli M, Zulato E, Rulli E, Marabese M, Centonze G, Busico A, Pastorino U, de Braud FG, et al: Metformin enhances cisplatin-induced apoptosis and prevents resistance to cisplatin in Co-mutated KRAS/LKB1 NSCLC. J Thorac Oncol 13: 1692-1704, 2018

34. Livak KJ and Schmittgen TD: Analysis of relative gene expression data using real-time quantitative PCR and the 2(-Delta Delta C(T)) method. Methods 25: 402-408, 2001.

35. Ye J, Coulouris G, Zaretskaya I, Cutcutache I, Rozen S and Madden TL: Primer-BLAST: A tool to design target-specific primers for polymerase chain reaction. BMC Bioinformatics 13: 134, 2012.

36. Bremang M, Cuomo A, Agresta AM, Stugiewicz M, Spadotto V and Bonaldi T: Mass spectrometry-based identification and characterisation of lysine and arginine methylation in the human proteome. Mol Biosyst 9: 2231-2247, 2013. 
37. Cox J, Neuhauser N, Michalski A, Scheltema RA, Olsen J V and Mann M: Andromeda: A peptide search engine integrated into the MaxQuant environment. J Proteome Res 10: 1794-1805, 2011.

38. Szklarczyk D, Franceschini A, Wyder S, Forslund K, Heller D, Huerta-Cepas J, Simonovic M, Roth A, Santos A, Tsafou KP, et al: STRING v10: Protein-protein interaction networks, integrated over the tree of life. Nucleic Acids Res 43 (Database Issue) D447-D452, 2015

39. Franceschini A, Szklarczyk D, Frankild S, Kuhn M, Simonovic M, Roth A, Lin J, Minguez P, Bork P, von Mering C and Jensen LJ: STRING v9.1: Protein-protein interaction networks, with increased coverage and integration. Nucleic Acids Res 41 (Database Issue): D808-D815, 2013.

40. Campbell JD, Alexandrov A, Kim J, Wala J, Berger AH, Pedamallu CS, Shukla SA, Guo G, Brooks AN, Murray BA et al: Distinct patterns of somatic genome alterations in lung adenocarcinomas and squamous cell carcinomas. Nat Genet 48: 607-616, 2016.

41. Cerami E, Gao J, Dogrusoz U, Gross BE, Sumer SO, Aksoy BA, Jacobsen A, Byrne CJ, Heuer ML, Larsson E, et al: The cBio cancer genomics portal: An open platform for exploring multidimensional cancer genomics data. Cancer Discov 2: 401-404, 2012.

42. Roesch A, Vultur A, Bogeski I, Wang H, Zimmermann KM, Speicher D, Körbel C, Laschke MW, Gimotty PA, Philipp SE, et al: Overcoming intrinsic multidrug resistance in melanoma by blocking the mitochondrial respiratory chain of slow-cycling JARID1Bhigh cells. Cancer Cell 23: 811-825, 2013.

43. Mogami T, Yokota N, Asai-Sato M, Yamada R, Koizume S, Sakuma Y, Yoshihara M, Nakamura Y, Takano Y, Hirahara F, et al: Annexin A4 is involved in proliferation, chemo-resistance and migration and invasion in ovarian clear cell adenocarcinoma cells. PLoS One 8: e80359, 2013.

44. Li N, Huang HQ and Zhang GS: Association between SOD2 C47T polymorphism and lung cancer susceptibility: A meta-analysis. Tumor Biol 35: 955-959, 2014.

45. Morales DR and Morris AD: Metformin in cancer treatment and prevention. Annu Rev Med 66: 17-29, 2015.

46. Guertin DA and Sabatini DM: Defining the role of mTOR in cancer. Cancer Cell 12: 9-22, 2007.

47. Sharma A, Bandyopadhayaya S, Chowdhury K, Sharma T, Maheshwari R, Das A, Chakrabarti G, Kumar V and Mandal CC: Metformin exhibited anticancer activity by lowering cellular cholesterol content in breast cancer cells. PLoS One 14 $\mathrm{e} 0209435,2019$

48. Lee JO, Kang MJ, Byun WS, Kim SA, Seo IH, Han JA, Moon JW, Kim JH, Kim SJ, Lee EJ, et al: Metformin overcomes resistance to cisplatin in triple-negative breast cancer (TNBC) cells by targeting RAD51. Breast Cancer Res 21: 115, 2019.

49. Dang JH, Jin ZJ, Liu XJ, Hu D, Wang J, Luo Y and Li LL: Metformin in combination with cisplatin inhibits cell viability and induces apoptosis of human ovarian cancer cells by inactivating ERK 1/2. Oncol Lett 14: 7557-7564, 2017.

50. Riaz MA, Sak A, Erol YB, Groneberg M, Thomale J and Stuschke M: Metformin enhances the radiosensitizing effect of cisplatin in non-small cell lung cancer cell lines with different cisplatin sensitivities. Sci Rep 9: 1282, 2019.

51. Zhang JW, Zhao F and Sun Q: Metformin synergizes with rapamycin to inhibit the growth of pancreatic cancer in vitro and in vivo. Oncol Lett 15: 1811-1816, 2018.

52. Jin DH, Kim Y, Lee B, Han J, Kim HK, Shim YM and Kim DH: Metformin induces cell cycle arrest at the G1 phase through E2F8 suppression in lung cancer cells. Oncotarget 8: 101509-101519, 2017.

53. Queiroz EAIF, Puukila S, Eichler R, Sampaio SC, Forsyth HL, Lees SJ, Barbosa AM, Dekker RF, Fortes ZB and Khaper N: Metformin induces apoptosis and cell cycle arrest mediated by oxidative stress, AMPK and FOXO3a in MCF-7 breast cancer cells. PLoS One 9: e98207, 2014.

54. Xie W, Wang L, Sheng H, Qiu J, Zhang D, Zhang L, Yang F, Tang D and Zhang K: Metformin induces growth inhibition and cell cycle arrest by upregulating MicroRNA34a in renal cancer cells. Med Sci Monit 23: 29-37, 2017.

55. Lundholm L, Hååg P, Zong D, Juntti T, Mörk B, Lewensohn R and Viktorsson K: Resistance to DNA-damaging treatment in non-small cell lung cancer tumor-initiating cells involves reduced DNA-PK/ATM activation and diminished cell cycle arrest. Cell Death Dis 4: e478, 2013.
56. Chatterjee A, Mukhopadhyay S, Tung K, Patel D and Foster DA Rapamycin-induced G1 cell cycle arrest employs both TGF- $\beta$ and $\mathrm{Rb}$ pathways. Cancer Lett 360: 134-140, 2015.

57. Lu Z, Peng K, Wang N, Liu HM and Hou G: Downregulation of p70S6K enhances cell sensitivity to rapamycin in esophageal squamous cell carcinoma. J Immunol Res 2016: 7828916, 2016.

58. Song J, Wang X, Zhu J and Liu J: Rapamycin causes growth arrest and inhibition of invasion in human chondrosarcoma cells. J BUON 21: 244-251, 2016.

59. Wang Y, Xu W, Yan Z, Zhao W, Mi J, Li J and Yan H: Metformin induces autophagy and G0/G1 phase cell cycle arrest in myeloma by targeting the AMPK/mTORC1 and mTORC2 pathways. J Exp Clin Cancer Res 37: 63, 2018.

60. Zhong DS, Sun LL and Dong LX: Molecular mechanisms of LKB1 induced cell cycle arrest. Thorac Cancer 4: 229-233, 2013

61. Zhang Y, Bao C, Mu Q, Chen J, Wang J, Mi Y, Sayari AJ, Chen Y and Guo M: Reversal of cisplatin resistance by inhibiting PI3K/Akt signal pathway in human lung cancer cells. Neoplasma 63: 362-370, 2016.

62. Sheng J, Shen L, Sun L, Zhang X, Cui R and Wang L: Inhibition of PI3K/mTOR increased the sensitivity of hepatocellular carcinoma cells to cisplatin via interference with mitochondrial-lysosomal crosstalk. Cell Prolif 52: e12609, 2019.

63. Hou G, Yang S, Zhou Y, Wang C, Zhao W and Lu Z: Targeted inhibition of mTOR signaling improves sensitivity of esophageal squamous cell carcinoma cells to cisplatin. J Immunol Res 2014 845763, 2014

64. Zhao Y, Sun H, Feng M, Zhao J, Zhao X, Wan Q and Cai D: Metformin is associated with reduced cell proliferation in human endometrial cancer by inbibiting PI3K/AKT/mTOR signaling. Gynecol Endocrinol 34: 428-432, 2018.

65. Galluzzi L, Senovilla L, Vitale I, Michels J, Martins I, Kepp O, Castedo M and Kroemer G: Molecular mechanisms of cisplatin resistance. Oncogene 31: 1869-1883, 2012.

66. Galluzzi L, Vitale I, Michels J, Brenner C, Szabadkai G, Harel-Bellan A, Castedo M and Kroemer G: Systems biology of cisplatin resistance: Past, present and future. Cell Death Dis 5: e1257, 2014

67. Pandey A and Mann M: Proteomics to study genes and genomes. Nature 405: 837-846, 2000

68. Chang X, Ravi R, Pham V, Bedi A, Chatterjee A and Sidransky D: Adenylate kinase 3 sensitizes cells to cigarette smoke condensate vapor induced cisplatin resistance. PLoS One 6: e20806, 2011.

69. Wei Y, Wu S, Xu W, Liang Y, Li Y, Zhao W and Wu J: Depleted aldehyde dehydrogenase 1A1 (ALDH1A1) reverses cisplatin resistance of human lung adenocarcinoma cell A549/DDP. Thorac Cancer 8: 26-32, 2017.

70. Morimoto A, Serada S, Enomoto T, Kim A, Matsuzaki S, Takahashi T, Ueda Y, Yoshino K, Fujita M, Fujimoto M, et al: Annexin A4 induces platinum resistance in a chloride-and calcium-dependent manner. Oncotarget 5: 7776-7787, 2014.

71. Feng X, Liu H, Zhang Z, Gu Y, Qiu H and He Z: Annexin A2 contributes to cisplatin resistance by activation of JNK-p53 pathway in non-small cell lung cancer cells. J Exp Clin Cancer Res 36: 123, 2017.

72. Becker M, De Bastiani MA, Müller CB, Markoski MM, Castro MA and Klamt F: High cofilin-1 levels correlate with cisplatin resistance in lung adenocarcinomas. Tumor Biology 35 : $1233-1238,2014$

73. Wittig R, Nessling M, Will RD, Mollenhauer J, Salowsky R, Münstermann E, Schick M, Helmbach H, Gschwendt B, Korn B, et al: Candidate genes for cross-resistance against DNA-damaging drugs. Cancer Res 62: 6698-6705, 2002.

74. Zeller C, Dai W, Steele NL, Siddiq A, Walley AJ, Wilhelm-Benartzi CS, Rizzo S, van der Zee A, Plumb JA and Brown R: Candidate DNA methylation drivers of acquired cisplatin resistance in ovarian cancer identified by methylome and expression profiling. Oncogene 31: 4567-4576, 2012

75. Yang M, Li Y, Shen X, Ruan Y,Lu Y, Jin X, Song P, Guo Y, Zhang X, Qu H, et al: CLDN6 promotes chemoresistance through GSTP1 in human breast cancer. J Exp Clin Cancer Res 36: 157, 2017.

76. Zhang R, Tao F, Ruan S, Hu M, Hu Y, Fang Z, Mei L and Gong C: The TGF $\beta 1$-FOXM1-HMGA1-TGF $\beta 1$ positive feedback loop increases the cisplatin resistance of non-small cell lung cancer by inducing G6PD expression. Am J Transl Res 11: 6860-6876, 2019

77. Wang JM, Liu BQ, Zhang Q, Hao L, Li C, Yan J, Zhao FY, Qiao HY, Jiang JY and Wang HQ: ISG15 suppresses translation of ABCC2 via ISGylation of hnRNPA2B1 and enhances drug sensitivity in cisplatin resistant ovarian cancer cells. Biochim Biophys Acta Mol Cell Res 1867: 118647, 2020. 
78. Di Martino S, Amoreo CA, NuvoliB, GalatiR,Strano S,FaccioloF, Alessandrini G, Pass HI, Ciliberto G, Blandino G, et al: HSP90 inhibition alters the chemotherapy-driven rearrangement of the oncogenic secretome. Oncogene 37: 1369-1385, 2018

79. Qin X, Sun L and Wang J: Restoration of microRNA-708 sensitizes ovarian cancer cells to cisplatin via IGF2BP1/Akt pathway. Cell Biol Int 41: 1110-1118, 2017.

80. Xu Z, Zou L, Ma G, Wu X, Huang F, Feng T, Li S, Lin Q, He X, Liu $\mathrm{Z}$ and Cao $\mathrm{X}$ : Integrin $\beta 1$ is a critical effector in promoting metastasis and chemo-resistance of esophageal squamous cell carcinoma. Am J Cancer Res 7: 531-542, 2017.

81. Li Y, Liu X, Lin X, Zhao M, Xiao Y, Liu C, Liang Z, Lin Z, Yi R, Tang Z, et al: Chemical compound cinobufotalin potently induces FOXO1-stimulated cisplatin sensitivity by antagonizing its binding partner MYH9. Signal Transduct Target Ther 4: 48, 2019.

82. Depeng S, Wu J, Guo L, Xu Y, Liu L and Lu J: Metformin increases sensitivity of osteosarcoma stem cells to cisplatin by inhibiting expression of PKM2. Int J Oncol 50: 1848-1856, 2017.

83. Zhu H, Wu J, Zhang W, Luo H, Shen Z, Cheng H and Zhu X: PKM2 enhances chemosensitivity to cisplatin through interaction with the mTOR pathway in cervical cancer. Sci Rep 6: 30788, 2016

84. Wang Y, Hao F, Nan Y, Qu L, Na W, Jia C and Chen X: PKM2 inhibitor shikonin overcomes the cisplatin resistance in bladder cancer by inducing necroptosis. International J Biol Sci 14 1883-1891, 2018

85. Krafft U, Tschirdewahn S, Hess J, Harke NN, Hadaschik BA, Nyirády P, Szendröi A, Szücs M, Módos O, Olah C, et al: STIP1 tissue expression is associated with survival in chemotherapy-treated bladder cancer patients. Pathol Oncol Res 26: 1243-1249, 2020.

86. Li C, Cai J, Ge F and Wang G: TGM2 knockdown reverses cisplatin chemoresistance in osteosarcoma. Int J Molr Med 42: 1799-1808, 2018

87. Yang H, Wu XL, Wu KH, Zhang R, Ju LL, Ji Y, Zhang YW, Xue SL, Zhang YX, Yang YF and Yu MM: MicroRNA-497 regulates cisplatin chemosensitivity of cervical cancer by targeting transketolase. Am J Cancer Res 6: 2690-2699, 2016.

88. Matassa DS,Amoroso MR,Lu H,Avolio R,ArzeniD,ProcacciniC, Faicchia D, Maddalena F, Simeon V, Agliarulo I, et al: Oxidative metabolism drives inflammation-induced platinum resistance in human ovarian cancer. Cell Death Differ 23: 1542-1554, 2016

89. Yue T, Zheng X, Dou Y, Zheng X, Sun R, Tian Z and Wei H: Interleukin 12 shows a better curative effect on lung cancer than paclitaxel and cisplatin doublet chemotherapy. BMC Cancer 16: $665,2016$.

90. Barros FBA, Assao A, Garcia NG, Nonogaki S, Carvalho AL, Soares FA, Kowalski LP and Oliveira DT: Moesin expression by tumor cells is an unfavorable prognostic biomarker for oral cancer. BMC Cancer 18: 53, 2018

91. Alam F, Mezhal F, El Hasasna H, Nair VA, Aravind SR, Saber Ayad M, El-Serafi A and Abdel-Rahman WM: The role of p53-microRNA 200-Moesin axis in invasion and drug resistance of breast cancer cells. Tumor Bio 39: 1010428317714634, 2017.

92. Wang Q, Lu X, Zhao S, Pang M, Wu X, Wu H, Hoffman RM, Yang $\mathrm{Z}$ and Zhang $\mathrm{Y}$ : Moesin expression is associated with glioblastoma cell proliferation and invasion. Anticancer Res 37: 2211-2218, 2017

93. Wang J, Gao Q, Wang D, Wang Z and Hu C: Metformin inhibits growth of lung adenocarcinoma cells by inducing apoptosis via the mitochondria-mediated pathway. Oncol Lett 10: 1343-1349, 2015.

94. Seguin L, Desgrosellier JS, Weis SM and Cheresh DA: Integrins and cancer: Regulators of cancer stemness, metastasis, and drug resistance. Trends Cell Biol 25: 234-240, 2015.

95. Blandin AF, Renner G, Lehmann M, Lelong-Rebel I, Martin S and Dontenwill M: $\beta 1$ integrins as therapeutic targets to disrupt hallmarks of cancer. Front Pharmacol 6: 279, 2015.

96. Ju L, Zhou C, Li W and Yan L: Integrin betal over-expression associates with resistance to tyrosine kinase inhibitor gefitinib in non-small cell lung cancer. J Cel Biochem 111: 1565-1574, 2010.

97. Kanda R, Kawahara A, Watari K, Murakami Y, Sonoda K, Maeda M, Fujita H, Kage M, Uramoto H, Costa C, et al: Erlotinib resistance in lung cancer cells mediated by integrin $\beta 1 / \mathrm{Src} / A k t-d r i v e n$ bypass signaling. Cancer Res 73: 6243-6253, 2013.

98. Gachechiladze M, Skarda J, Janikova M, Mgebrishvili G, Kharaishvili G, Kolek V, Grygarkova I, Klein J, Poprachova A, Arabuli M and Kolar Z: Overexpression of filamin-A protein is associated with aggressive phenotype and poor survival outcomes in NSCLC patients treated with platinum-based combination chemotherapy. Neoplasma 63: 274-281, 2016.
99. Ji ZM, Yang LL, Ni J, Xu SP, Yang C, Duan P, Lou LP and Ruan QR Silencing filamin a inhibits the invasion and migration of breast cancer cells by up-regulating 14-3-3б. Curr Med Sci 38: 461-466, 2018.

100. Li L, Lu Y, Stemmer PM and Chen F: Filamin A phosphorylation by Akt promotes cell migration in response to arsenic. Oncotarget 6: 12009-12019, 2015.

101. Guo Y, Li M, Bai G, Li X, Sun Z, Yang J, Wang L and Sun J: Filamin a inhibits tumor progression through regulating BRCA1 expression in human breast cancer. Oncol Lett 16: 6261-6266, 2018

102. Donadon M,Di Tommaso L, Soldani C, Franceschini B, Terrone A, Mimmo A, Vitali E, Roncalli M, Lania A and Torzilli G: Filamin A expression predicts early recurrence of hepatocellular carcinoma after hepatectomy. Liver Int 38: 303-311, 2018

103. Maynadier M, Farnoud R, Lamy PJ, Laurent-Matha V, Garcia M and Rochefort H: Cathepsin D stimulates the activities of secreted plasminogen activators in the breast cancer acidic environment. Int J Oncol 43: 1683-1690, 2013

104. Hah YS, Noh HS, Ha JH, Ahn JS, Hahm JR, Cho HY and Kim DR: Cathepsin D inhibits oxidative stress-induced cell death via activation of autophagy in cancer cells. Cancer Lett 323: 208-214, 2012.

105. Zhang C, Zhang M and Song S: Cathepsin D enhances breast cancer invasion and metastasis through promoting hepsin ubiquitin-proteasome degradation. Cancer Lett 438: 105-115, 2018.

106. Kang SW: Superoxide dismutase 2 gene and cancer risk: Evidence from an updated meta-analysis. Int J Clin Exp Med 8 14647-14655, 2015.

107. Lee JH, Choi IY, Kil IS, Kim SY, Yang ES and Park JW: Protective role of superoxide dismutases against ionizing radiation in yeast. Biochim Biophys Acta 1526: 191-198, 2001

108. Epperly MW, Gretton JE, Sikora CA, Jefferson M, Bernarding M, Nie S and Greenberger JS: Mitochondrial localization of superoxide dismutase is required for decreasing radiation-induced cellular damage. Radiat Res 160: 568-578, 2003

109. Takada Y, Hachiya M, Park SH, Osawa Y, Ozawa T and Akashi M: Role of reactive oxygen species in cells overexpressing manganese superoxide dismutase: Mechanism for induction of radioresistance. Mol Cancer Res 1: 137-146, 2002.

110. Hosoki A, Yonekura S, Zhao QL, Wei ZL, Takasaki I, Tabuchi Y, Wang LL, Hasuike S, Nomura T, Tachibana A, et al: Mitochondria-targeted superoxide dismutase (SOD2) regulates radiation resistance and radiation stress response in HeLa cells J Radiat Res 53: 58-71, 2012

111. Cruz-Bermúdez A, Laza-Briviesca R, Vicente-Blanco RJ, García-Grande A, Coronado MJ, Laine-Menéndez S, Palacios-Zambrano S, Moreno-Villa MR, Ruiz-Valdepeñas AM, Lendinez C, et al: Cisplatin resistance involves a metabolic reprogramming through ROS and PGC-1 $\alpha$ in NSCLC which can be overcome by OXPHOS inhibition. Free Radic Biol Med 135 $167-181,2019$

112. Zuo J, Zhao M, Liu B, Han X, Li Y, Wang W, Zhang Q, Lv P, Xing L, Shen $H$ and Zhang X: TNF- $\alpha$-mediated upregulation of SOD-2 contributes to cell proliferation and cisplatin resistance in esophageal squamous cell carcinoma. Oncol Rep 42: 1497-1506, 2019.

113. Yan X, Pan L, Yuan Y, Lang JH and Mao N: Identification of platinum-resistance associated proteins through proteomic analysis of human ovarian cancer cells and their platinum-resistant sublines. J Proteome Res 6: 772-780, 2007.

114. Matsuzaki S, Enomoto T, Serada S, Yoshino K, Nagamori S, Morimoto A, Yokoyama T, Kim A, Kimura T, Ueda Y, et al: Annexin A4-conferred platinum resistance is mediated by the copper transporter ATP7A. Int J Cancer 134: 1796-1809, 2014.

115. Yao HS, Sun C, Li XX, Wang Y, Jin KZ, Zhang XP and Hu ZQ Annexin A4-nuclear factor- $\kappa \mathrm{B}$ feedback circuit regulates cell malignant behavior and tumor growth in gallbladder cancer. Sci Rep 6: 31056, 2016.

116. Yamashita T, Nagano K, Kanasaki S, Maeda Y, Furuya T, Inoue M, Nabeshi H, Yoshikawa T, Yoshioka Y, Itoh N, et al: Annexin A4 is a possible biomarker for cisplatin susceptibility of malignant mesothelioma cells. Biochem Biophys Res Commun 421: 140-144, 2012.

117. Vizcaíno JA, Deutsch EW, Wang R, Csordas A, Reisinger F, Ríos D, Dianes JA, Sun Z, Farrah T, Bandeira N, et al: ProteomeXchange provides globally coordinated proteomics data submission and dissemination. Nat Biotechnol 32: 223-226, 2014

This work is licensed under a Creative Commons Attribution-NonCommercial-NoDerivatives 4.0 International (CC BY-NC-ND 4.0) License. 